\title{
Genome-Wide CRISPR Screen Identifies Non-Canonical NF-kB Signaling as a Potent Regulator of Density-dependent Proliferation
}

\author{
Maria Fomicheva and lan G. Macara* \\ Dept. of Cell and Developmental Biology \\ Vanderbilt University School of Medicine \\ Nashville TN37240
}

${ }^{*}$ Address correspondence to:

Ian Macara, Ph.D.

Louise B. McGavock Professor, and Chair

Dept. of Cell and Developmental Biology

Vanderbilt University School of Medicine

PMB 407935

U 3209 MRB III

Nashville TN 37240-7935

USA

Tel: 615-875-5565

Email: ian.g.macara@vanderbilt.edu 


\section{ABBREVIATIONS}

CKI - cyclin-dependent kinase inhibitor

DPC - days post-confluency

FDR - false discovery rate

$\mathrm{FUCCI}$ - fluorescence ubiquitination cell cycle indicator

gDNA - genomic DNA

IPA - Ingenuity Pathway Analysis

$\mathrm{KO}$ - knockout

NT - non-targeted sgRNA control

qPCR - quantitative PCR

RRA - robust ranking aggregation

WT - wild type 


\section{ABSTRACT}

Epithelial cells possess intrinsic mechanisms to maintain an appropriate cell density for normal tissue morphogenesis and homeostasis. Defects in such mechanisms likely contribute to hyperplasia and cancer initiation. To identify genes that regulate the density-dependent proliferation of murine mammary epithelial cells, we developed a fluorescence-activated cell sorting assay based on $\mathrm{FUCCl}$, which marks different stages of the cell cycle with distinct fluorophores. Using this powerful assay, we performed a genome-wide CRISPR/Cas9 knockout screen, selecting for cells that proliferate normally at low density but continue to divide at high density. Unexpectedly, one top hit was Traf3, a negative regulator of NF-kB signaling that has never previously been linked to density-dependent proliferation. We demonstrate that loss of Traf3 specifically activates non-canonical NF-kB signaling. This in turn triggers an innate immune response and drives cell division independently of known density-dependent proliferation mechanisms, including YAP/TAZ signaling and cyclin kinase inhibitors, by blocking entry into quiescence.

\section{INTRODUCTION}

An important characteristic of epithelial cells is that, unlike fibroblasts, they do not undergo contact inhibition but continue to proliferate at confluence. This behavior enables the expansion of epithelial tissues during organismal growth without compromising the barrier function created by intercellular junctions. Importantly, however, proliferation is not indefinite but terminates at a preset cell density (Fomicheva et al., 2019). Stretching or wounding an epithelial sheet, which reduces the cell density, can re-initiate cell division (Aragona et al., 2013). Conversely, compression, which increases density, can result in extrusion and apoptosis of cells so as to bring the epithelial layer back to its homeostatic state (Eisenhoffer et al., 2012). This control mechanism that prevents tissue overgrowth is essential for normal development, and it is lost in hyperplasia and in cancer. However, the mechanisms that underlie homeostatic cell density maintenance remain incompletely understood.

One system through which epithelial cells can respond to changes in density is the Hippo pathway and its effectors YAP and TAZ. These transcriptional co-activators are nuclear at low cell density or under conditions of high mechanical strain, but become phosphorylated and are cytoplasmic (or junction-associated) and nonfunctional at high density and/or low strain (Dupont et al., 2011). Independently of YAP/TAZ, however, the polarity proteins LGL1/2 can also control density-dependent proliferation, by inhibiting proteasomal degradation of the cyclin-dependent 
kinase inhibitor p27. Loss of LGL1/2 reduces the expression of $p 27$, which is often upregulated at high cell density to arrest proliferation (Yamashita et al., 2015). Numerous studies on Hippo/YAP have demonstrated the complexity of this pathway, and several novel Hippo pathway components have been revealed over the past few years. In addition, as mentioned previously, Hippoindependent mechanisms have also been recently reported, such as the LGL/p27 pathway. It is therefore likely that other Hippo pathway components and/or currently unknown Hippoindependent signaling mechanisms exist, however no strategy has been designed to identify such mechanisms.

With the goal of discovering novel factors that regulate epithelial homeostasis, we developed a powerful new assay based on a fluorescence activated cell sorting (FACS) approach that we integrated with a genome-wide CRISPR-Cas9 sgRNA knockout (KO) screen to select for genes that are essential for cell cycle arrest at high density, but which do not impact proliferation of cells below the threshold for arrest. The screen employs a fluorescence ubiquitination cell cycle indicator (FUCCI) system to mark proliferating cells in S/G2/M phases of cell cycle with a green fluorescent protein, and cells in G1/G0 with a red fluorescent protein (Sladitschek and Neveu, 2015). We found that mammary EpH4 epithelial cells robustly arrest in G1 or G0 by 4 days postconfluency (DPC). When these cells were transduced with a pooled whole-genome CRISPR KO library, and then sorted 4 DPC for cycling cells, we identified several candidate genes that may regulate cell density-dependent proliferation activity. The top hit was Nf2 (also called Merlin), a known tumor suppressor that negatively regulates YAP/TAZ, which validated our approach (Petrilli and Fernandez-Valle, 2016). A second, unexpected hit was Traf3, a negative regulator of NF-KB signaling, which has never previously been reported to regulate cell density-dependent proliferation. We demonstrate that loss of Traf3 robustly and specifically activates the noncanonical NF-kB pathway. This in turn triggers an innate immune response and cell autonomously drives cell division independently of both YAP/TAZ signaling and cyclin kinase inhibitors, overriding these classical mechanisms of density-dependent proliferation control and preventing cells at high density from entering quiescence.

\section{RESULTS}

\section{A FUCCI-based screen for density-dependent cell cycle arrest}

Our goal was to design a screen for the rapid and efficient selection of epithelial cells that continue to proliferate inappropriately at high cell density. For the screen, we needed to identify a cell line that retained epithelial features, including homeostatic density control. We chose the 
murine EpH4 mammary epithelial cell line for this screen, because EpH4 cells are highly polarized, form confluent epithelial sheets, and, most importantly, we confirmed that they efficiently arrest at high density. We also needed a tool to specifically identify and select cells that maintain proliferative activity at high density. To distinguish cycling from non-cycling cells, we established a stable EpH4 line that expresses ES-FUCCI, which labels cells in G1/G0 with mCherry and cells in S/G2/M with mCitrine (Figure 1A) (Sladitschek and Neveu, 2015). As expected, the EpH4-FUCCI cells remain proliferative at 1 DPC but very few cells cycle at high density, with only about $1 \%$ of cells expressing mCitrine at 4 DPC (Figure 1B, Figure 1 - figure supplement $1 \mathrm{~A})$. 
A

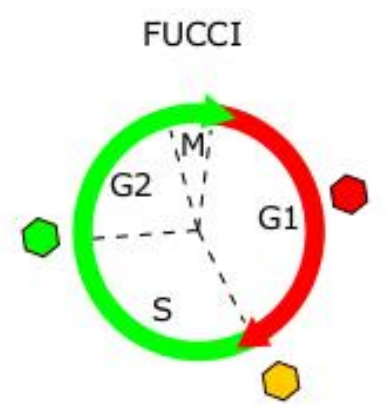

D
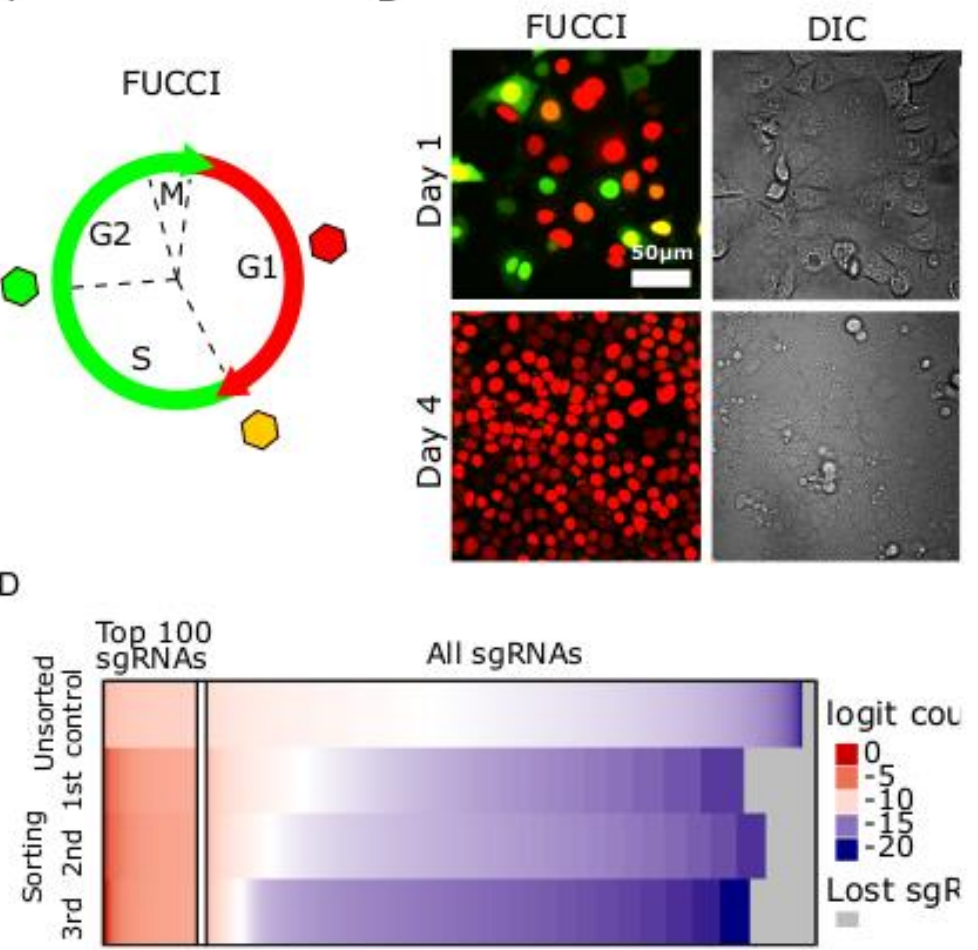

C

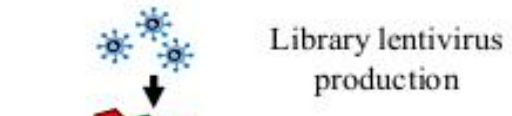

Transduction of EpH4-FUCCI cells

Grow cells to high density

Select dividing cells with FACS

Re-plate cells

Purify gDNA

PCR up sgDNAs

Attach Illumina primers

Illumina NGS
E

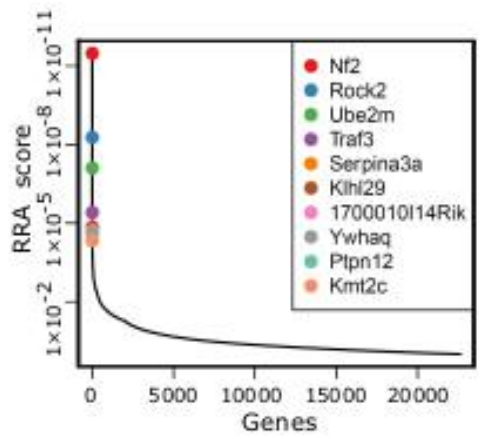

F

\begin{tabular}{|c|c|c|c|}
\hline Rank & ID & FDR & $\begin{array}{c}\text { Enriched/total } \\
\text { sgRNAs }\end{array}$ \\
\hline 1 & Nf2 & 0.00248 & $6 / 6$ \\
2 & Rock2 & 0.00248 & $6 / 6$ \\
3 & Ube $2 m$ & 0.01155 & $6 / 6$ \\
4 & Traf3 & 0.09777 & $4 / 6$ \\
5 & Serpina3a & 0.2203 & $3 / 6$ \\
6 & Klh/29 & 0.2203 & $3 / 6$ \\
\hline
\end{tabular}

Figure 1. Whole-genome screening for genes that inhibit proliferation at homeostatic cell density. (A) A Schematic of FUCCI color transitions through cell cycle. (B) EpH4-FUCCI stable cell line grown at 1 and 4 DPC. (C) Whole-genome CRISPR KO screening strategy. (D) Read count distribution for samples before sorting and after different rounds of sorting. Data are logit transformed $\left(f(p)=\log _{2}(p / 1-p)\right.$ where $p$ is the proportion of a given sgRNA in the total number of sgRNAs in a sample). Color coding shows depleted sgRNAs in blue, enriched sgRNAs in red and sgRNA with no enrichment in white. Gray shows lost sgRNAs. (E) Genes plotted based on their RRA enrichment score ( $3^{\text {rd }}$ sorting). (F) List of genes with FDR below 0.25 and $>=3$ sgRNAs enriched compared to control after $3^{\text {rd }}$ sort. 
We reasoned that the expression of any shRNA or sgRNA that disrupts expression of a gene involved in density-dependent arrest could be identified by employing FACS to enrich for green cells from an EpH4-FUCCI population grown to high density. To test this concept, we used a shRNA lentiviral construct to deplete the cyclin-dependent kinase inhibitor $p 27$, which is known to be associated with cell cycle arrest post-confluency (Yamashita et al., 2015). Quantitative PCR for the $p 27$ transcript showed that $\sim 60 \%$ of $p 27$ mRNA was lost in cells expressing the $p 27$ shRNA (Figure 1 - figure supplement 1B) compared to EpH4-FUCCI cells expressing scrambled shRNA. The p27-depleted cells display increased cell proliferation after 4 DPC, in contrast to cells expressing scrambled shRNA (Figure 1 - figure supplement 1A). As a proof-of-principle experiment, we next mixed wild type (WT) EpH4-FUCCI cells and sh-p27 EpH4-FUCCI cells at a 10:1 ratio (Figure 1 - figure supplement $1 \mathrm{C}$ ). The mixed cells were then plated at a cell density of 100,000 cells $/ \mathrm{cm}^{2}$, such that they reached confluency $24 \mathrm{hrs}$ after seeding. We grew the mixture of cells for 4 DPC and sorted mCitrine-positive (mCitrine+) cells by FACS. After sorting, we isolated genomic DNA (gDNA) and performed qPCR using primers against the puromycin gene, located in the lentiviral plasmid insert, to assess the fraction of p27-depleted cells in the cell mixture. We observed an average of $1.4 x$ and $3.5 x$ enrichment of the puromycin gene after the $1^{\text {st }}$ and $2^{\text {nd }}$ rounds of sorting, respectively (Figure 1 - figure supplement $1 \mathrm{D}$ ). These data support the validity of our screen design.

Based on these encouraging results, we proceeded to developing an EpH4-FUCCI cell line, in which every cell has lost a single gene. We transduced EpH4-FUCCI cells with the pooled GeCKO CRISPR v2 KO lentivirus library (Shalem et al., 2014, Sanjana et al., 2014). (Figure 1D). The library contains 6 sgRNAs against each of 20,611 genes, plus 1000 non-targeting controls, for a total of 130,209 sgRNAs. To ensure that our EpH4-FUCCI cells would receive only 1 sgRNA on average, we transduced cells with viruses at a multiplicity of infection (MOI) of 0.3. It is critical to maintain a large enough cell population to ensure that all sgRNAs in the library are retained. Therefore, we aimed to have 150-300 cells per sgRNA in each step of the screen. Based on these values, $6.7 \times 10^{7} \mathrm{EpH} 4-\mathrm{FUCCI}$ cells were transduced to obtain about $2 \times 10^{7}$ cells that had acquired viruses ( 150 cells per sgRNA). Cells that were not infected with virus were eliminated by puromycin selection. We plated the cells at 100,000 cells $/ \mathrm{cm}^{2}$ and grew them for 4 DPC. To maintain library representation, we sorted $4 \times 10^{7}$ cells (300 cells per sgRNA) by FACS to select mCitrine+ cells. We re-grew cells for the next round of selection and for gDNA isolation. In total, we performed three FAC sorts. We observed a steady increase in the number of mCitrine+ cells after each round of FACS (Figure 1 - figure supplement 1E, F). Genomic DNA was purified, and integrated sgRNA cassettes were amplified from the DNA by PCR, as described previously 
(Shalem et al., 2014, Sanjana et al., 2014) (Figure 1 - figure supplement 2A, B). A second PCR reaction attached Illumina index primers (Figure 1 - figure supplement 2A, C), and the pooled product was then sequenced.

We used the MAGeCK program (Li et al., 2014) to map sequencing reads to the library (Figure 1E, Figure 1 - figure supplement 2D, D'). Read count distribution was relatively uniform in the control (unsorted) sample, with depletion of those sgRNAs that target essential genes. After each round of selection, more sgRNAs were depleted, but a small portion of sgRNAs was highly enriched. We utilized the MAGeCK algorithm to find genes that were enriched after sorts compared to control. MAGeCK takes into account changes in the abundance of all sgRNAs targeting a single gene, measured by the robust ranking aggregation (RRA) score. The most enriched genes have the smallest RRA scores (Figure 1F, Figure 1 - figure supplement 2E, E'). We selected genes with FDR below 0.25 and with 3 or more sgRNAs/gene selected (Figure 1G, Figure 1 - figure supplement $2 \mathrm{~F}, \mathrm{~F}^{\prime}$ ).

\section{The CRISPR screen identifies a component of the Hippo pathway, a lymphocyte proliferation control factor and NEDD8-conjugating E2 enzyme}

Interestingly, the top enriched target was Nf2/Merlin, which is a known tumor suppressor gene and a regulator of Hippo signaling necessary for cell density control (Petrilli and FernandezValle, 2016). This hit, the sgRNAs for which were enriched by $>1000 x$ above the control abundance, strongly validated our screening strategy. Two unexpected hits were for the Traf3 and Ube2m (Ubc12) genes (Figure 1G), which have not previously been implicated in densitydependent cell cycle arrest.

TRAF3 (TNF Receptor Associated Factor 3) is critical for lymphocyte proliferation control and immune responses (Zapata et al., 2009). It negatively regulates signaling through multiple pathways, including the canonical and non-canonical NF-kB pathways (He et al., 2006, Ramakrishnan et al., 2004, Zarnegar et al., 2008, Sun, 2017).

Deletions and mutations of TRAF3 are among the most common genetic alterations in human B cell malignancies (Zhu et al., 2018). B cell-specific KO of the Traf3 gene in mice leads to increased B cell numbers and spontaneous lymphomas (Moore et al., 2012). Myeloid-specific Traf3 KO causes histiocytic sarcomas of macrophage origin (Lalani et al., 2015). Therefore, TRAF3 is critical for the prevention of malignant growth in blood cells; however, TRAF3 roles in epithelia have not yet been widely investigated, despite its ubiquitous expression in mouse and human tissues (Yue et al., 2014). 
A third hit from our screen was Ube2m (Ubiquitin Conjugating Enzyme E2 M, also known as Ubc12). UBE2M is a NEDD8 conjugation E2 enzyme, which neddylates CULLIN-RING ligases to stimulate their activity (Lydeard et al., 2013). Interestingly, stress induces UBE2M expression and promotes its ubiquitylation of UBE2F, the degradation of which can suppress cell proliferation (Zhou et al., 2018).

To confirm that loss of our top candidates indeed results in over-proliferation at high density, we developed two new sgRNA CRISPR v2 plasmids per gene. The sgRNA sequences were different from those in the GeCKO library. We transduced EpH4 cells with these sgRNA lentiviruses and confirmed efficient $\mathrm{KO}$ of each gene by immunoblotting for NF2, TRAF3 and UBE2M (Figure 2A-C'). To test if loss of the target genes leads to a failure in cell cycle arrest at high density, we analyzed BrdU incorporation at 1 and 4 DPC. BrdU was added to cells for $1 \mathrm{hr}$, then cells were fixed and stained. When cells had just reached a confluent state, we found that BrdU incorporation was similar for the non-targeted sgRNA control (NT) and each of the KO cell lines, but that at high density the KO cells incorporated more BrdU than did the NT control cells (Figure 2D). These differences were statistically significant at high density, as determined by cytometric analysis of BrdU+ cells (Figure 2E, F, Figure 2 - figure supplement $1 \mathrm{~A}$ ). We also observed that all three $\mathrm{KO}$ cell lines formed multiple layers at high density, while control cells remained as a single, uniform layer (Figure 2G, H, Figure 2 - figure supplement 1B). Together, these data demonstrate that our screen successfully identified genes that are essential for the restriction of proliferation at high cell density. Importantly, loss of these genes has no effect on the cell cycle at lower densities. 


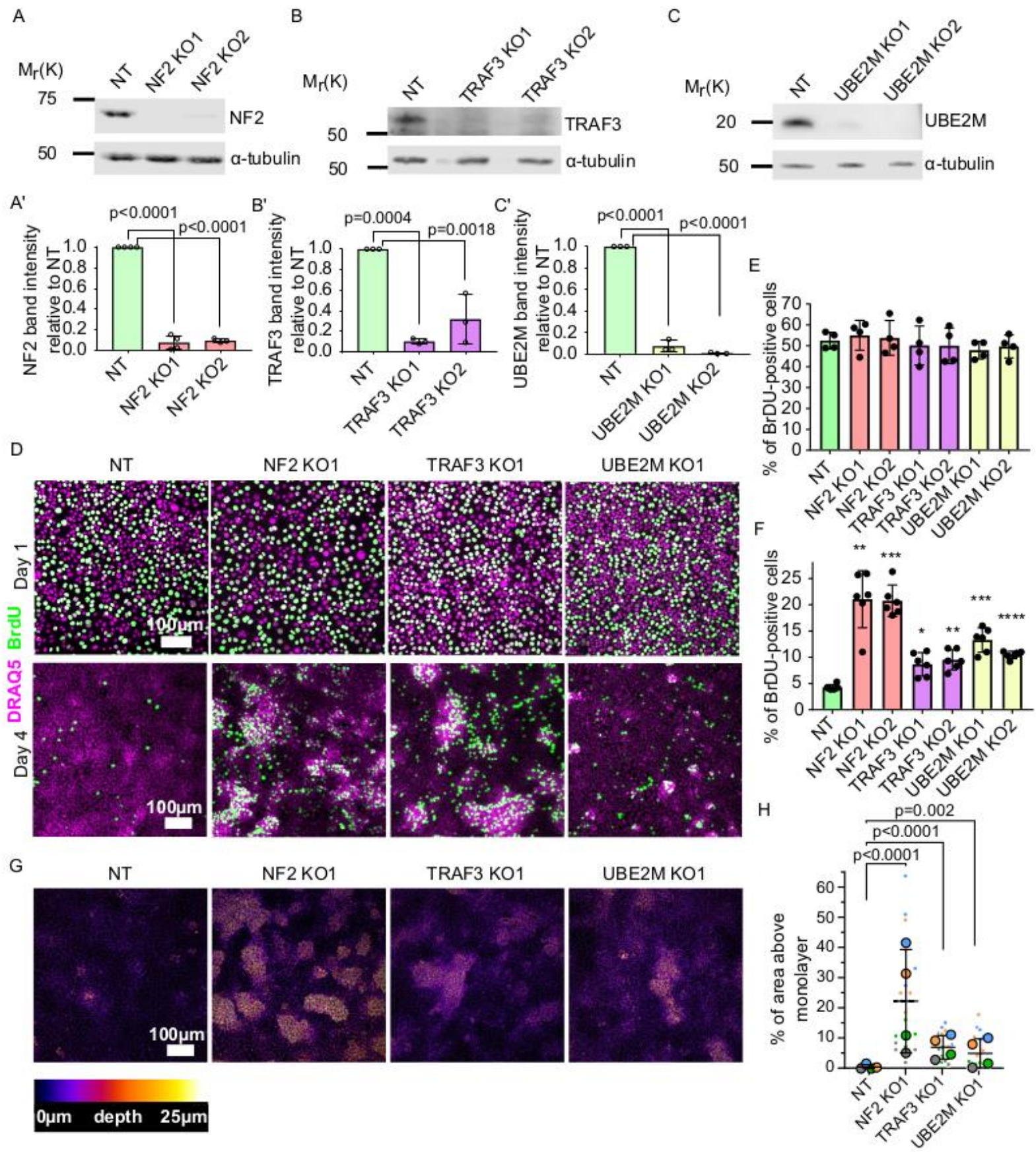

Figure 2. Validation of candidate genes identified from the screen. (A) - (C) Immunoblots of NT control and NF2 (A), TRAF3 (B) and UBE2M (C) KO EpH4 cells for NF2, TRAF3 and UBE2M, respectively. $\alpha$-tubulin or GAPDH was used as a loading control. (A') - (C') Quantification of NF2 $\left(A^{\prime}\right)$, TRAF3 (B') and UBE2M (C') levels based on immunoblotting in $(A)$ - $(C)$. $\left(A^{\prime}\right)$ - $\left(C^{\prime}\right)$ Histograms show mean \pm 1 s.d. $(n=3)$. $P$ values were calculated by one-way ANOVA followed by Dunnett's multiple comparisons test. (D) NT control, NF2, TRAF3 and UBE2M KO cells grown for 1 or 4 DPC. BrdU was added for $1 \mathrm{hr}$, then cells were fixed and stained for BrdU, with DAPI as a 
nuclear marker. (E), (F) Cytometric analysis of NT control, NF2, TRAF3 and UBE2M KO cells stained for BrdU to assess proliferation at 1 or 4 DPC, respectively. $N=4$ (E) and $n=6(F)$ Histograms show mean \pm 1 s.d. $P$ values were calculated by one-way ANOVA followed by Dunnett's multiple comparisons test. (G) Control and KO cells stained with Hoechst dye. Confocal images are depth color coded. The color code scale is shown below. (H) 5 fields of view in 4 biological repeats were used to quantify the level of multilayering. Data shown as a SuperPlot (Lord et al., 2020). P values were calculated by mixed model two-way ANOVA. 
TRAF3 suppresses proliferation of mammary organoids, human mammary epithelial cells and fibroblasts

Little is known about the function of TRAF3 in epithelial cells, and its role in densitydependent cell cycle arrest has not been previously investigated. Interestingly, however, genetic alterations in Traf3 occur in a variety of human epithelial cancers, though at a level $<6 \%$ (Zhu et al., 2018). Low Traf3 mRNA expression is also associated with significantly worse survival for lung and gastric cancer patients (Figure 2 - figure supplement 1C) (Nagy et al., 2018). Therefore, we focused on this gene for further analysis.

To determine the generality of the phenotype induced by deletion of Traf3, we first asked if the effects are confined to the EpH4 mammary epithelial line or are also important in primary mammary tissue. To address this question, we used murine mammary organoids, which recapitulate many aspects of normal morphogenesis of the mammary gland (Pasic et al., 2011, Ewald et al., 2008). Mammary gland ductal fragments were isolated from WT C3H mice, transduced with lentivirus, and then grown as organoids in Matrigel culture, as described previously (Pasic et al., 2011) (Figure 3A). As shown in Figure 3B, WT organoids form buds with hollow lumens, but organoids lacking TRAF3 formed multilayered buds with small or no detectable lumens. Additionally, staining for phospho-HISTONE H3 revealed a substantially higher mitotic index in organoids deleted for Traf3, compared to organoids transduced with a control sgRNA (Figure 3B, C), demonstrating that TRAF3 normally suppresses WT tissue overgrowth.

To extend our analysis across species, we transduced the normal human mammary gland cell line MCF10A with sgRNAs designed to target human Traf3. Loss of the gene product was confirmed by immunoblotting (Figure 3 - figure supplement 1A, $A^{\prime}$ ). We assessed cell proliferation by immunofluorescence and cytometric analysis of BrdU incorporation as described above, and found that, similar to EpH4 cells, MCF10a TRAF3 KO cells, but not WT MCF10a cells, overproliferate at high density (Figure 3 - figure supplement 1B, B').

Finally, we determined if this role for TRAF3 is confined to epithelial cells, by knocking out the gene in NIH 3T3 fibroblasts. Normally, these cells contact-inhibit at high density. CRISPR KO of Traf3 (confirmed by Western blotting (Figure 3 - figure supplement 1D-D')) promoted cell proliferation at high density as measured by cytometric analysis of BrdU staining (Figure 3 - figure supplement 1D-D'). These data suggest that loss of TRAF3 broadly interferes with cell cycle arrest including cells of epithelial and mesenchymal lineages. 
A

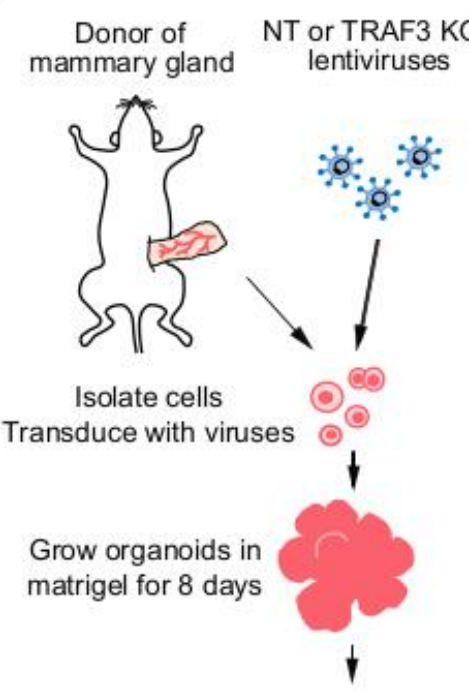

Fix and stain
B

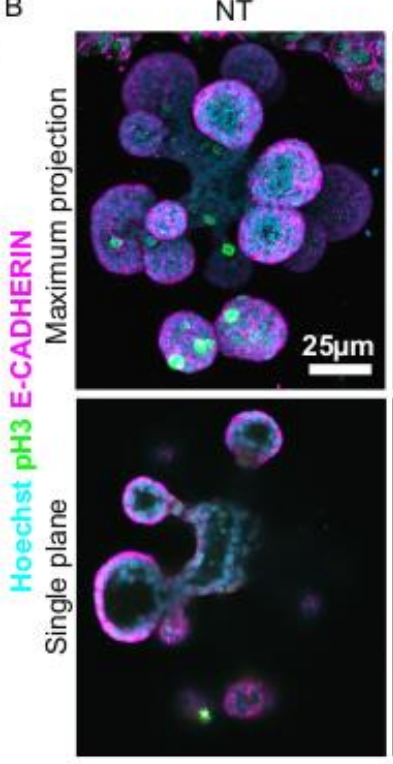

TRAF3 KO1

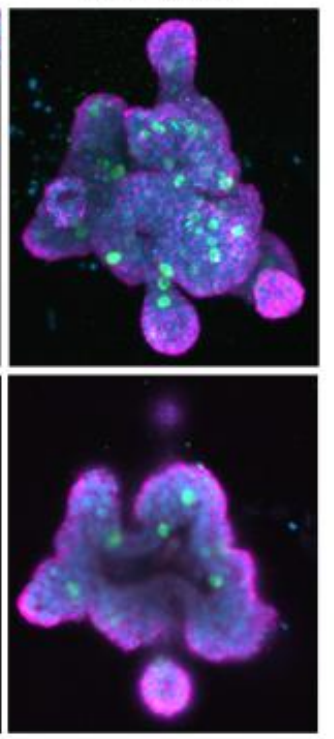

C

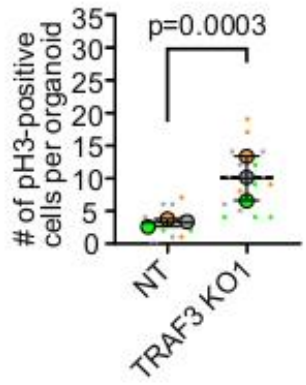

Figure 3. Loss of TRAF3 causes over-proliferation in primary mammary organoids. (A) Primary mammary organoid experiment workflow. (B) Maximum intensity projection of NT and TRAF3 KO1 mammary organoids stained for phospho-HISTONE H3 (pH3), E-CADHERIN and DNA (Hoechst). Bottom panel - single confocal plane of NT and TRAF3 KO1 organoids. (C) Quantifications of the number of pH3-positive cells per organoid; 5-10 organoids of comparable size were quantified per condition per repeat. Data shown as a SuperPlot $(n=3)$. $P$ values were calculated by mixed model two-way ANOVA. 


\section{Loss of TRAF3 activates non-canonical NF-KB signaling to promote over-proliferation}

How does TRAF3 regulate proliferation? We hypothesized that TRAF3 might be involved in the same pathways as in blood cells, where it negatively regulates both the canonical and noncanonical NF-kB pathways (He et al., 2006, Ramakrishnan et al., 2004, Zarnegar et al., 2008, Sun, 2017). In the non-canonical pathway, TRAF3 constitutively promotes proteasomal degradation of NIK, a kinase that is essential for activation of the downstream signaling cascade. Ligand recruitment to an upstream receptor triggers TRAF3 poly-ubiquitinylation and degradation. As a result, NIK levels increase, and it phosphorylates its downstream target IKKa, which in turn phosphorylates the p100 REL family protein. Phosphorylated p100 is partially degraded to $\mathrm{p} 52$, which enters the nucleus in association with RELB and regulates the transcription of target genes (Sun, 2017).

To test if loss of TRAF3 activates non-canonical NF-KB signaling, we examined the location of RELB in control and TRAF3 KO EpH4 cells and primary mammary gland organoids (Figure 4A-C). As expected, RELB was predominantly cytoplasmic in control cells and organoids. However, loss of TRAF3 caused a substantial nuclear accumulation, indicative of non-canonical NF-KB activation. We also performed immunoblotting for non-canonical NF-KB signaling components in control and TRAF3 KO cells at 1 and 4 DPC (Figure 4D, E). TRAF3 KO cells at both 1 and 4 DPC had substantially increased NIK levels and enhanced processing of p100 to p52 compared to NT control cells. However, cell density differences had no impact on NIK, RELB, TRAF3 and p100/p52 protein levels. Therefore, TRAF3 KO leads to activation of non-canonical NF-KB signaling, but regulation of these pathway components is independent of cell density.

Based on previous literature, we predicted that loss of TRAF3 could also stimulate canonical NF-kB signaling (Figure 4F). IKB normally blocks RELA/p65 and p50 from entering the nucleus, but activation of upstream kinases $\mathrm{IKK \alpha} / \beta$ by phosphorylation induces IKB phosphorylation and degradation (Ramakrishnan et al., 2004, Zarnegar et al., 2008). Surprisingly, however, RELA/p65 did not accumulate in the nuclei of TRAF3 KO cells (Figure 4G). Immunoblotting for the canonical NF-KB pathway components showed activation of IKKa/ $\beta$ phosphorylation at high density both in control and TRAF3 KO cells; but no IKB degradation was observed in control and TRAF3 KO cells either at low or at high density (Figure 4H). Together, these data demonstrate that in mammary epithelial cells, the loss of TRAF3 specifically activates non-canonical but not canonical NF-KB signaling. 
A

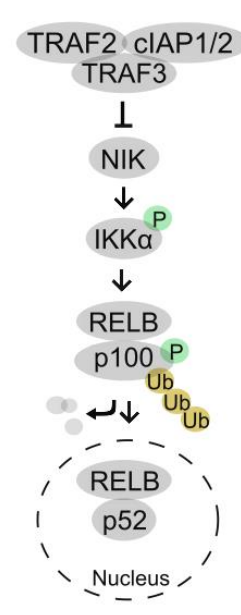

B

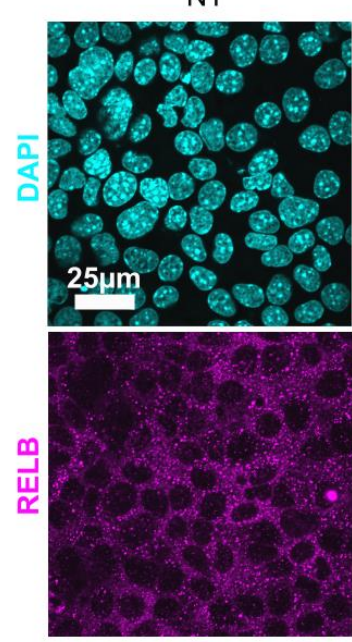

TRAF3 KO1

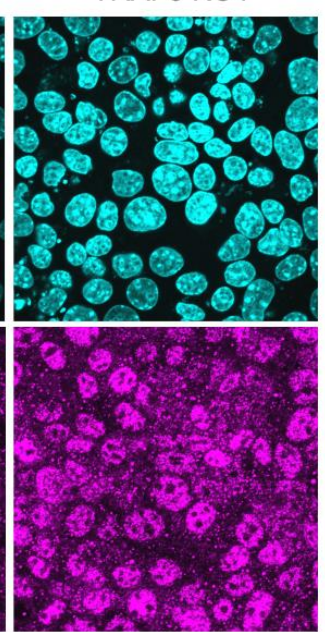

C

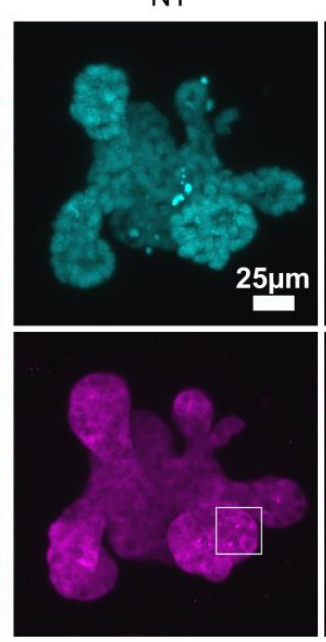

TRAF3 KO1

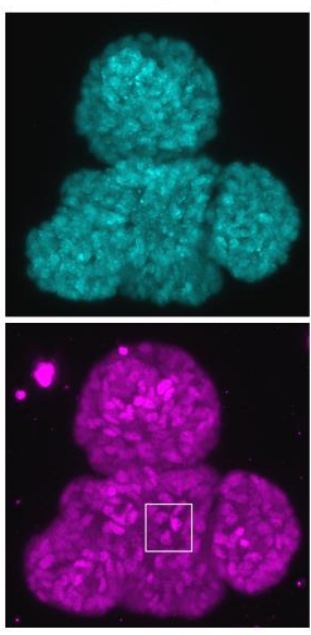

E
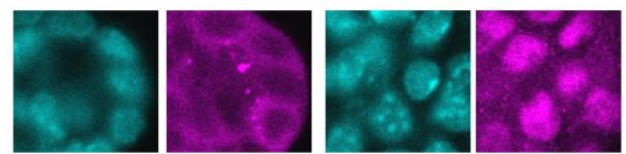
$\left.\mathrm{Mr}_{\mathrm{r}} \mathrm{K}\right) \frac{\text { Day } 1}{-+} \frac{\text { Day } 4}{-+ \text { TRAF3 KO }}$ $100-\div-\mathrm{p} 100$ $50--\mathrm{p} 52$ $50-\approx--\infty$-tubulin

G
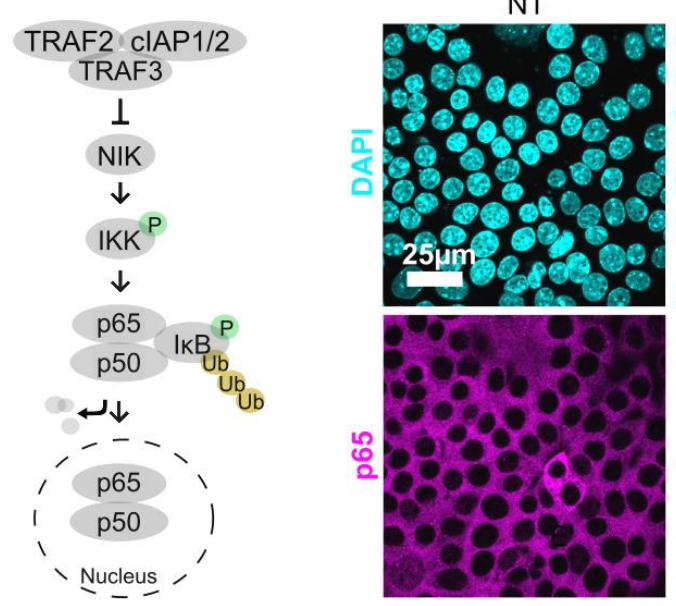

TRAF3 KO1

$\mathrm{H}$

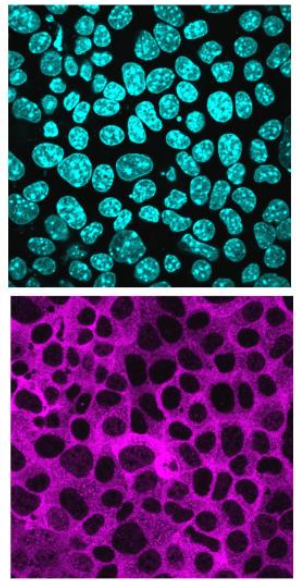

Figure 4. Loss of TRAF3 specifically activates non-canonical but not canonical NF-kB pathway. (A) Simplified schematic of non-canonical NF-KB pathway. TRAF3 sends NIK for degradation. In the absence of TRAF3, NIK levels increase, and it activates the downstream cascade, resulting in increased p100 processing to p52. RELB/p52 enters the nucleus where it regulates transcription of target genes. In experiments (B) - (C) RELB localization was tested in NT and TRAF3 KO1 cells. (B) - (C) Fluorescence staining of NT and TRAF3 KO1 EpH4 cells (B) and organoids $(\mathrm{C})$ with anti-RELB antibodies and DAPI. (B) - single confocal planes. (C) - maximum 
intensity projection. White boxed ROls are shown in enlarged images as single confocal planes. (D) Immunoblots of NT and TRAF3 KO1 lysates grown to 1 or 4 DPC probed for NIK, RELB, TRAF3 and actin as loading control. (E) Immunoblots of NT and TRAF3 KO1 lysates grown to 1 or 4 DPC probed for p100/p52 and $\alpha$-tubulin as loading control. (F) A schematic of TRAF3dependent activation of canonical NF-kB pathway. (G) Fluorescence staining of NT and TRAF3 KO1 cells with antibodies against p65 and with DAPI. (G) Western blotting of NT and TRAF3 KO1 cells at 1 DPC and 4 DPC probed for components of canonical NF-KB pathway and GAPDH as loading control 
If TRAF3 affects cell proliferation via the non-canonical NF-KB pathway, then deletion of p100 in TRAF3 KO cells should reduce proliferation to control levels (Figure 5A). To test this prediction, we generated a lentivector encoding a p100 sgRNA, plus GFP as a selection marker. We transduced $\mathrm{EpH} 4$ cells with virus and isolated GFP+ cells by FACS. Immunoblotting confirmed efficient knockout of p100 in NT control and TRAF3 KO cells (Figure 5B, B'). Blotting also showed increased cleavage of p100 to p52 in TRAF3 KO cells as compared to control cells (Figure 5B), and both bands were lost in cells expressing the p100 sgRNA, confirming that the detected 52 $\mathrm{kDa}$ band is indeed the product of $\mathrm{p} 100$. We next grew cells to high density and analyzed pulsed BrdU incorporation by flow cytometry. There was no significant difference between control and NT/p100 KO cells, indicating that TRAF3 does not regulate cell cycling at low cell density. The proliferation of TRAF3/p100 double KO cells was, however, substantially reduced compared to TRAF3 KO cells (Figure $5 \mathrm{C}$, D) demonstrating that non-canonical NF-KB signaling is required for the phenotype induced by loss of TRAF3.

As a further test, we knocked out the effector kinase NIK. Immunoblotting (Figure 5E, E') revealed that, as expected, NIK is undetectable in NT control cells, but accumulates in TRAF3 $\mathrm{KO}$ cells. However, expression was lost in TRAF3/NIK double KO cells. Similar to p100 KO, deletion of NIK caused reduced proliferation in TRAF3 KO cells (Figure 5F, G).

To further confirm that non-canonical NF-KB pathway is necessary for the high density over-proliferation phenotype, we treated cells with BV6, a selective inhibitor of IAP proteins. clAP1/2 is a part of the TRAF3 complex that degrades NIK. Therefore, we predicted that treatment with BV6 would induce over-proliferation. We treated cells with BV6 at low and high density (Figure $5 \mathrm{H}$ and I, respectively) and observed that BV6 treatment induces over-proliferation of NT cells at high density but not at low density, as shown by cytometric analysis of BrdU staining (Figure $5 \mathrm{H}, \mathrm{I})$.

We next asked if the non-canonical NF-kB pathway is sufficient to induce overproliferation. We cloned and over-expressed a mutant NIK protein lacking the TRAF3-binding motif (NIK- $\Delta$ T3) (Liao et al., 2004), to prevent NIK degradation (Figure 5J). Flow cytometry and immunofluorescent staining showed strong over-proliferation of NT NIK- $\Delta$ T3 cells at 4 DPC compared to NT control cells (Figure 5K, L) demonstrating that activation of non-canonical NF-KB pathway is sufficient for increased proliferation at high density.

We conclude that TRAF3 normally suppresses proliferation at high cell density via inhibition of the non-canonical NF-KB pathway, but does not impact proliferation at lower cell density. This pathway does not contribute to proliferation in WT EpH4 cells, but is constitutively 
bioRxiv preprint doi: https://doi.org/10.1101/2020.10.02.324301; this version posted October 2, 2020. The copyright holder for this preprint

(which was not certified by peer review) is the author/funder, who has granted bioRxiv a license to display the preprint in perpetuity. It is made available under aCC-BY-NC-ND 4.0 International license.

activated by loss of TRAF3. Activation of non-canonical NF-kB pathway downstream of TRAF3 is both necessary and sufficient for over-proliferation phenotype at high density. 
A

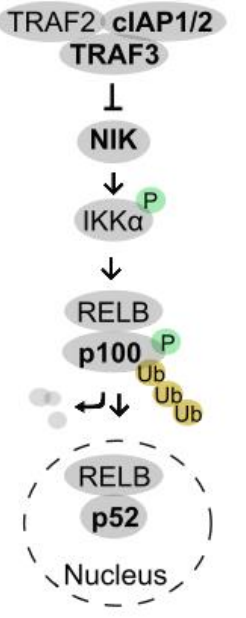

$\mathrm{E}$

G

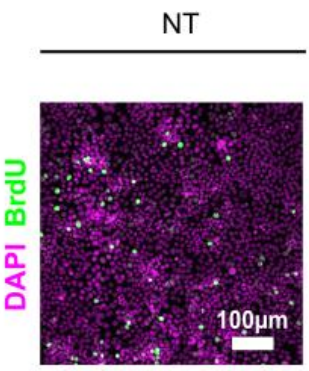

J

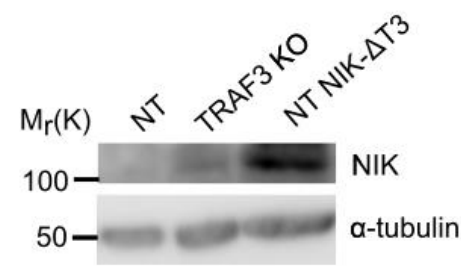

$E^{\prime}$
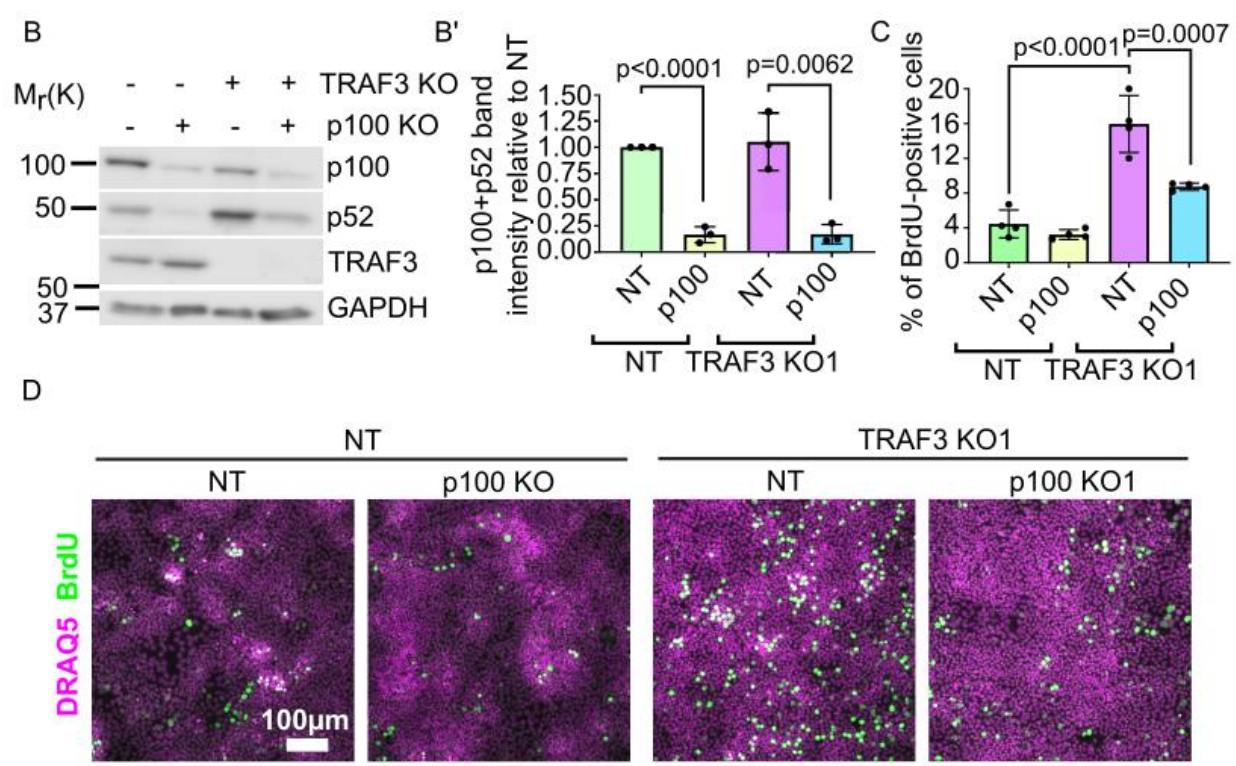

NT
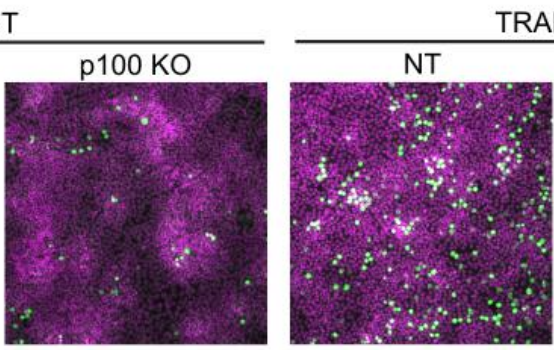

$\mathrm{F}$
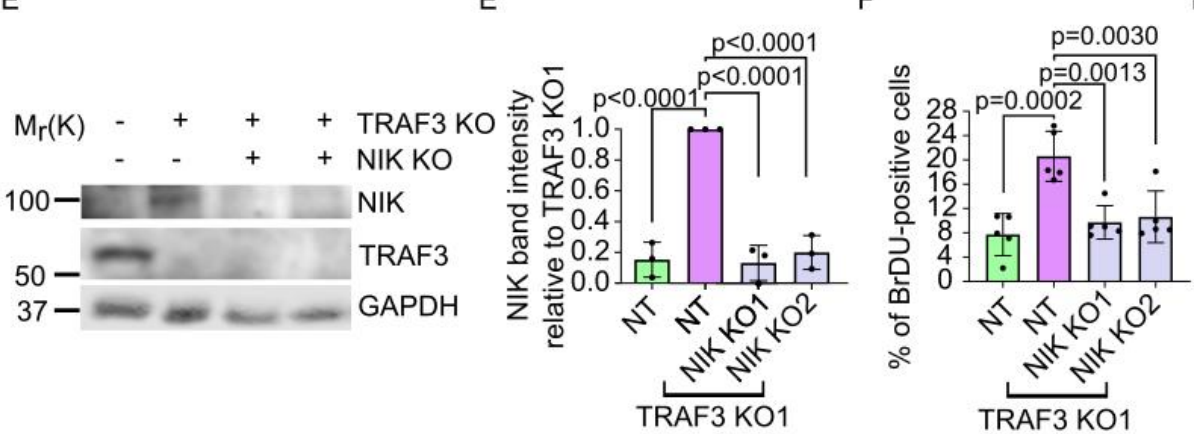

$\mathrm{H}$

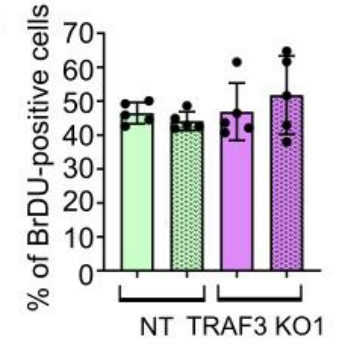

$\mathrm{DMSO}+-+-$

BV6 $7 \mu \mathrm{M}-++$

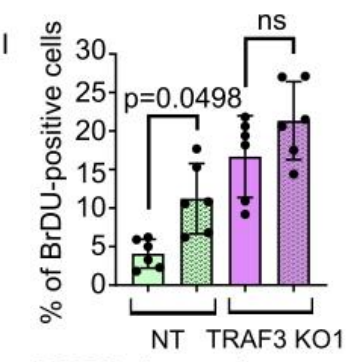

$\mathrm{DMSO}+-+-$

BV6 $7 \mu \mathrm{M}-++$

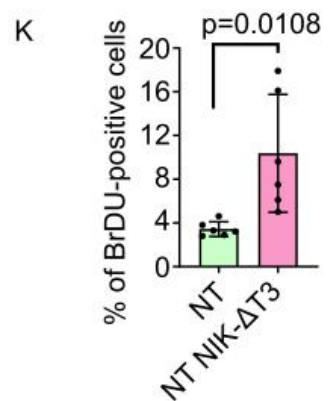

L

NT

NT NIK- $\Delta$ T3
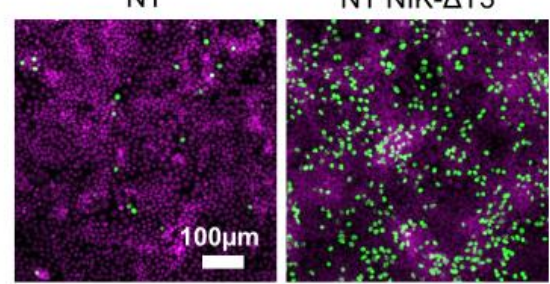

Figure 5. Non-canonical NF-KB signaling is necessary and sufficient for over-proliferation in TRAF3 KO cells. (A) Non-canonical NF-kB pathway schematic. Proteins shown in bold were 
manipulated in this study. (B) Immunoblotting of NT and TRAF3 KO1 cells transduced with pLVTHM GFP NT or p100 sgRNAs. Blot was stained for p100/p52, TRAF3 and GAPDH (loading control). (B') Quantifications of Western blot (B), histogram shows mean \pm 1 s.d. $(n=3)$. P values were calculated by Student's t-test. (C) Cytometric analysis of NT and TRAF3 KO cells transduced with pLVTHM GFP NT or p100 sgRNAs. Graph shows mean \pm s.d. $(n=4)$. P values were calculated by one-way ANOVA followed by Tukey's multiple comparisons test. (D) NT and TRAF3 KO1 cells transduced with pLVTHM GFP NT or $p 100$ sgRNAs were treated with BrdU at 4 DPC and immunostained for BrdU and DAPI. (E) Immunoblot of NT and TRAF3 KO1 cells transduced with NT, NIK KO1 or KO2. Blot was stained for NIK, TRAF3 and GAPDH (loading control). (E') Quantifications of Western blot (E) Histogram shows mean $\pm 1 \mathrm{~s} . \mathrm{d}(\mathrm{n}=3)$. $P$ values were calculated by one-way ANOVA followed by Tukey's multiple comparisons test. (F) Cytometric analysis of NT cells and TRAF3 KO1 cells transduced with control NT, NIK KO1 and KO2. Histogram shows mean \pm 1 s.d. $(n=5)$. P values were calculated by one-way ANOVA followed by Tukey's multiple comparisons test. (G) NT and TRAF3 KO1 cells transduced with control NT, NIK KO1 and KO2 were treated with BrdU at 4 DPC and immunostained for BrdU and DAPI. (H), (I) Cytometric analysis of NT and TRAF3 KO cells treated with $7 \mu \mathrm{M}$ BV6 at low $(\mathrm{H})$ and high $(\mathrm{I})$ density. Histogram shows mean \pm 1 s.d. $(n=5(H), n=6(I))$. P values were calculated by one-way ANOVA followed by Dunnett's $(\mathrm{H})$ or Tukey's $(\mathrm{I})$ multiple comparisons test $(\mathrm{J})$ Immunoblot of NT, TRAF3 KO1 (positive control) and NT cells expressing pWPI mScarlet NIK $\Delta$ T3. Blot was stained for NIK and GAPDH (loading control). (K) Cytometric analysis of NT cells and NT pWPI mScarlet NIK $\Delta T 3$ cells. Histogram shows mean \pm 1 s.d. $(n=6)$. $P$ values were calculated by Student t-test. $(L)$ NT and NT pWPI mScarlet NIK $\triangle$ T3 cells were treated with BrdU at 4 DPC and immunostained for BrdU and DAPI. 


\section{Non-canonical NF-kB signaling activates an innate immune response}

Our data show that the loss of TRAF3 results in increased levels of the transcription factor p52, which is necessary for over-proliferation. However, gene expression changes downstream of non-canonical NF-kB signaling have not been investigated in epithelia; nor is it known which genes are targets of p52 in epithelial cells. Therefore, to identify downstream effectors of TRAF3 and non-canonical NF-KB signaling, we performed genome-wide transcriptomics analysis on NT control cells, TRAF3 KO, and TRAF3/p100 double KO cells. For these studies, we used our EpH4FUCCI mammary epithelial cell line, which was transduced with NT, Traf3, or Traf3 plus p100 sgRNA lentiviruses, and sorted for G1/G0 phase (mCherry+) cells (Figure 6A). This strategy eliminates indirect gene expression differences reflective of the larger fraction of cycling (mCitrine+) cells caused by loss of TRAF3, but will not remove constitutive changes in gene expression.

Two biological replicates of each cell line were processed, and fastq files were analyzed using CLC Genomics Workbench and Ingenuity Pathway Analysis (IPA). Differential gene expression was filtered for $>2$-fold differences, FDR $<0.05$. Surprisingly, IPA did not detect any stimulation by TRAF3 KO of those signaling pathways classically involved in proliferation, including PI3K/AKT, JNK, TGF- $\beta$, WNT and Hippo (Figure 6B). There was, however, a dramatic induction of innate immune response genes. Antigen presentation, interferon response genes and genes responsible for foreign DNA and RNA recognition were strongly upregulated by deletion of TRAF3 (Figure 6B-E). Additionally, TRAF3 KO cells over-express adhesion molecules Icam1 and Vcam1 that facilitate adhesion of recruited leukocytes (Figure 6F). Superoxide-producing NADPH-oxidase complex genes, which eliminate bacteria and fungi, were also induced (Figure $6 \mathrm{G}$ ), as were several chemokines and growth factors (Figure $6 \mathrm{H}$ ), but some genes that normally respond to pathogens, such as defensins, IL-8, and IL-17, were not affected.

The comparison of TRAF3 KO and TRAF3/p100 double KO samples revealed that not all pathways activated by TRAF3 KO could be reversed by blocking non-canonical NF-KB signaling. We found that $\mathrm{p} 100 \mathrm{KO}$ partially reduces antigen presentation gene expression, the interferon response pathway, and foreign DNA and RNA recognition genes (Figure 6B-E), but differential gene expression of other pathways was not significantly changed. These data argue that antigen presentation, interferon pathways and foreign DNA and RNA recognition genes are downstream targets of non-canonical NF-KB signaling in mammary epithelial cells. However, none of these pathways are likely to promote cell proliferation. Rather, the data suggest that non-canonical NF$\mathrm{KB}$ signaling instead suppresses signals that normally would cause cell cycle exit. 
A

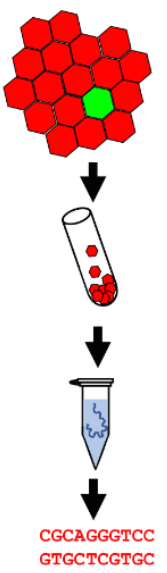

Grow EpH4-FUCCI NT, TRAF3 KO1 and TRAF3/p100 double $\mathrm{KO}$ cells to high density

Select non-dividing cells with FACS

RNA isolation

Fragmentation and cDNA synthesis

RNAseq
B

NT vs. TRAF3 KO1

-log10(p-value)

Antigen Presentation Pathway

Interferon Signaling

PI3K/AKT Signaling

SAPK/JNK Signaling

TGF- $\beta$ Signaling

$W n t / \beta$-catenin Signaling

Hippo Signaling -

TRAF3 KO1 vs. TRAF3/p100 double KO

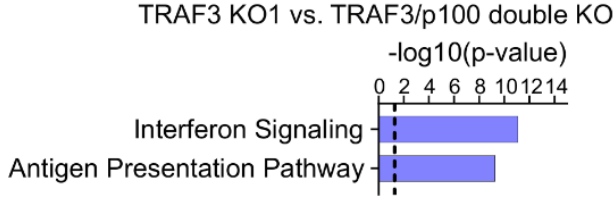

C

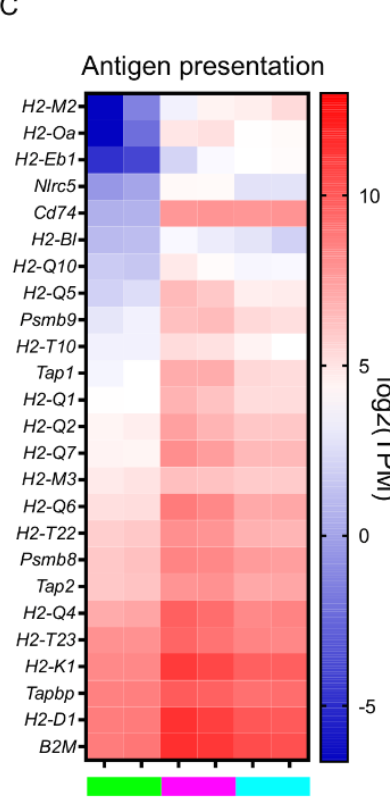

D

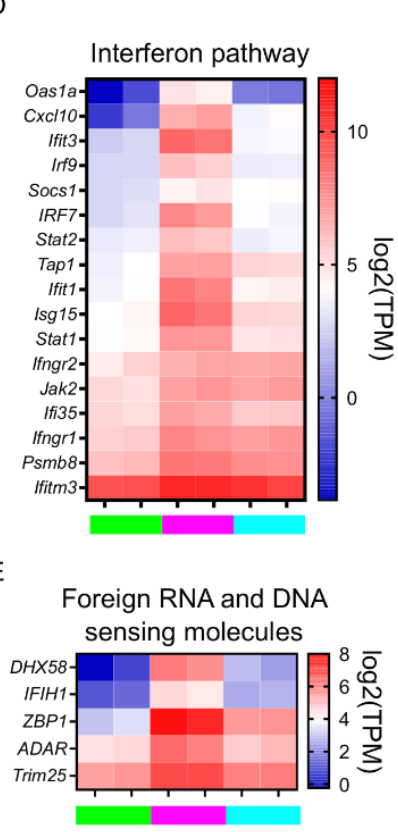

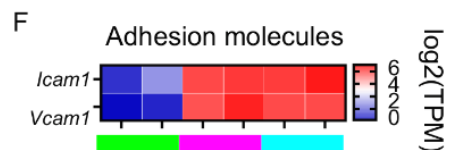

G

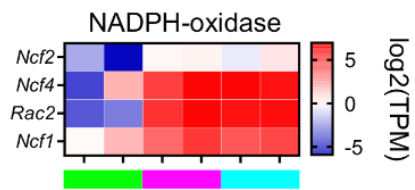

$\mathrm{H}$

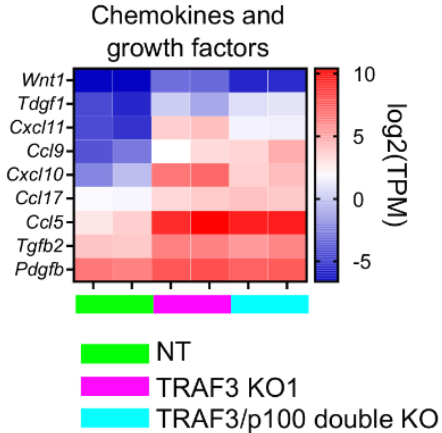

Figure 6. Loss of TRAF3 in EpH4 cells induces immune response pathways. (A) RNAseq experiment workflow. (B) Ingenuity Pathway Analysis (IPA) of RNAseq data showing significant upregulation of pathways related to infection response in TRAF3 $\mathrm{KO}$ cells compared to NT control (top, pink bars), and significant reduction of these pathways in TRAF3/p100 double KO cells compared to TRAF3 KO cells (bottom, blue bars). Notably, Hippo signaling and other pathways that regulate proliferation were unchanged. Threshold line is $p<0.05$. (C)- $(H)$. Heatmaps comparing mRNA levels of antigen presentation (C), interferon (D), foreign RNA and DNA recognition (E) pathway components, adhesion molecules (F), NADPH-oxidase components $(G)$, 
bioRxiv preprint doi: https://doi.org/10.1101/2020.10.02.324301; this version posted October 2, 2020. The copyright holder for this preprint

(which was not certified by peer review) is the author/funder, who has granted bioRxiv a license to display the preprint in perpetuity. It is made available under aCC-BY-NC-ND 4.0 International license.

chemokines and growth factors $(\mathrm{H})$ between NT, TRAF3 KO1 and TRAF3/p100 double KO in two experimental repeats. NT, TRAF3 KO1 and TRAF3/p100 double KO are color-coded with green, purple and light blue, respectively. Data are presented as log2 of transcripts per million (TPM). 


\section{Loss of TRAF3 does not affect YAP signaling}

Hippo/YAP signaling is a key mechanism that prevents abnormal proliferation at high density. Therefore, we tested whether the response to deletion of TRAF3 is independent of this pathway. The transcriptional co-activator YAP, a downstream effector of Hippo, is nuclear at low cell density and promotes cell cycling, but becomes phosphorylated and is cytoplasmic at high density (Ma et al., 2019). Therefore, we asked if loss of TRAF3 induces YAP translocation to the nucleus. We immunostained control, NF2 KO cells (positive control) and TRAF3 KO cells with anti-YAP antibodies. In dense cultures, YAP was predominantly cytoplasmic in the NT control cells, but nuclear in NF2 KO cells, as expected. However, deletion of TRAF3 did not induce significant nuclear accumulation of YAP, as compared to the NT control (Figure 7A, B). Moreover, comparison of expression profiles for conserved YAP target genes (Cordenonsi et al., 2011) from our RNAseq data showed an absence of any significant induction for more than $90 \%$ of conserved YAP target genes in TRAF3 KO cells compared to the NT control (Figure 7C). We conclude, therefore, that TRAF3 loss promotes over-proliferation independently of YAP, a major regulator of cell density-dependent proliferation. 
A

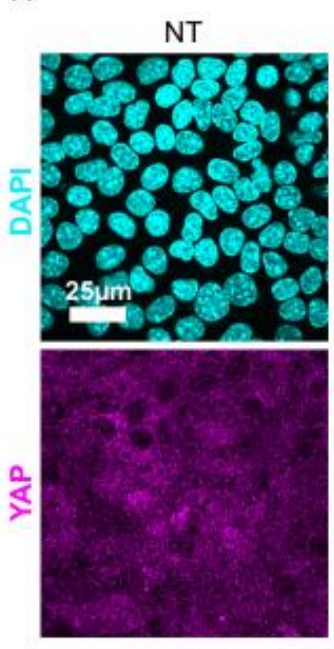

NF2 KO1

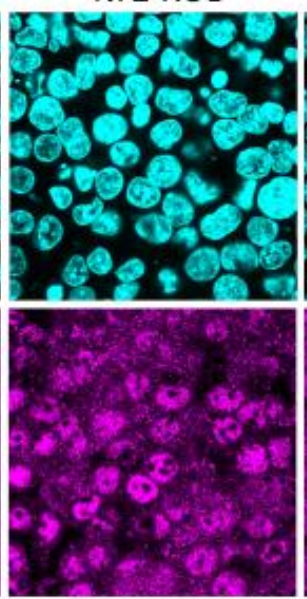

TRAF3 KO1

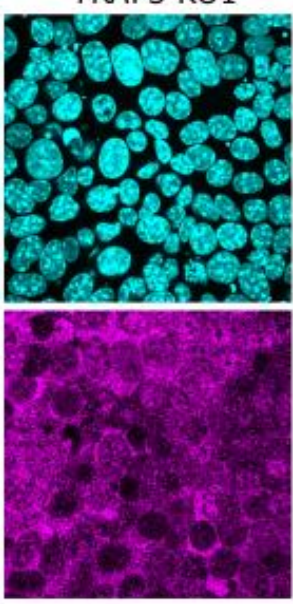

B

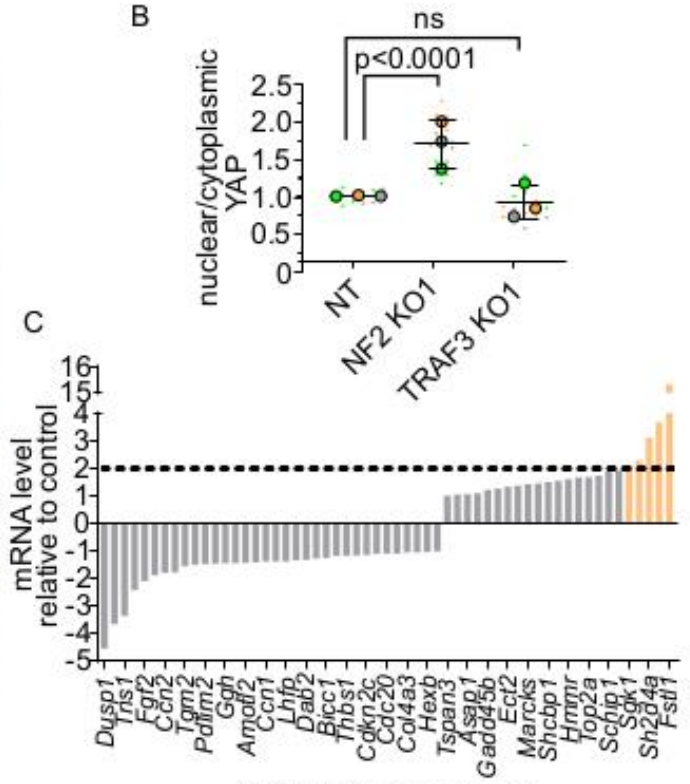

C

YAP/TAZ target genes

Figure 7. YAP/TAZ signaling is not activated by loss of TRAF3. (A) NT, NF2 KO1 and TRAF3 KO1 cells stained for YAP and DAPI. (B) Quantifications of nuclear to cytoplasmic YAP ratio in NT, NF2 KO1 and TRAF3 KO1 cells. Measurements were of at least 12 fields of view per condition per experimental replicate, and the average ratio was calculated. Data are presented as a SuperPlot $(n=3)$. P values were calculated by mixed model two-way ANOVA. (C) Conserved YAP/TAZ gene signature expression in TRAF3 KO1 cells shown as fold differences between NT control and TRAF3 KO1. Dashed threshold line is based on 2x increase in gene expression. 


\section{The TRAF3 KO cell over-proliferation phenotype is cell autonomous}

Our RNAseq data showed that several secreted factors including chemokines and growth factors (Figure $6 \mathrm{H}$ ) are induced by loss of TRAF3, and we hypothesized that these factors might be secreted and trigger over-proliferation at high density in neighboring cells. To test this possibility, we labeled NT control cells with GFP and, separately, control or TRAF3 KO cells with mScarlet, then mixed red and green cells (NT + TRAF3 KO, or NT + NT) at a 1:1 ratio, and after 4 DPC stained them for the proliferation marker KI-67 and DAPI (Figure 7 - figure supplement 1A). Cytokines released from the TRAF3 KO cells could then, in principle, stimulate proliferation of surrounding NT (GFP+) control cells. However, there was no significant difference in the fraction of KI-67+ cells between NT GFP cells mixed with NT mScarlet and NT GFP cells mixed with TRAF3 KO mScarlet cells (Figure 7 - figure supplement 1B). These data strongly argue that the over-proliferation phenotype is cell autonomous, and is not a consequence of secreted cytokines or other factors.

\section{Loss of TRAF3 does not affect the levels of cyclin-dependent kinase inhibitors (CKIs)}

The p27 CKI has been reported to inhibit density-dependent proliferation in response to changes in LGL1/2 expression (Yamashita et al., 2015). Moreover, we demonstrated that shRNA knockdown of p27 can promote cell proliferation in EpH4 cells (Figure 1B, C, Figure 1 - figure supplement $1 \mathrm{~A}, \mathrm{~B})$. Therefore, we asked if the non-canonical NF-kB pathway suppresses CKI induction at high cell density. We immunoblotted for p27 and other CKIs including p21, p18 and p19, in subconfluent and dense (4 DPC) cultures of NT, NT/p100 KO, TRAF3 KO1, and TRAF3/p100 double KO cells (Figure 7 - figure supplement 2A-C). p21 levels were low in cells at low density, but were high in all dense cultures, irrespective of TRAF3 or p100 expression. No significant changes in any of the other CKIs we tested were detected at low versus high cell density, or in the absence of TRAF3 or p100 (Figure 7 - figure supplement 2A'-C'). These data argue that non-canonical NF-KB signaling overrides the ability of these CKIs to induce cell cycle arrest in $\mathrm{EpH} 4$ cells.

\section{Loss of TRAF3 blocks cells from entering G0}

It was previously shown that TRAF3 induces over-proliferation by triggering CYCLIN D1 (Demicco et al., 2005),(Park et al., 2006), (Rocha et al., 2003), (Zhang et al., 2007), (Cao et al., 2001). We analyzed CYCLIN D1 in dense TRAF3 KO cells compared to NT cells by immunofluorescence. Indeed, we observed a small increase of CYCLIN D1 levels in TRAF3 KO cells compared to control (Figure 8A, B). 
We hypothesized that loss of TRAF3 prevents cells from entering the G0 quiescent state. Through this mechanism loss of TRAF3 should give a proliferative advantage to cells not only at high density, but also under other challenging conditions, such as starvation, that also promote entry into G0. To test this idea, we grew NT and TRAF3 KO cells in normal medium or medium devoid of FBS (Figure 8C). We observed no difference in proliferation between NT and TRAF3 $\mathrm{KO}$ cells in normal medium after 1 DPC. However, starvation decreased proliferation in control cells but not in TRAF3 KO cells. These data suggest that loss of TRAF3 prevents cells from entering G0.

To further explore this possibility, we labeled control and TRAF3 KO cells with markers to differentiate quiescent and cycling cells. Cells exiting the cell cycle and entering G0 are known to have very low CDK2 activity. To determine if loss of TRAF3 prevents entry into G0, we used a previously validated biosensor, DHB-mVenus, which can quantitatively reveal CDK2 activity in live cells based on its distribution between the nucleus (G0/G1) and cytoplasm (G2/M) (Figure 8D) (Spencer et al., 2013, Gookin et al., 2017). As shown in Figure 8E and G, at high density control cells enter quiescence, with almost exclusive nuclear localization of the biosensor. In contrast, cells lacking TRAF3 show an increased percent of cytoplasmic DHB-mVenus localization at high density, consistent with them continuing in cycle instead of entering quiescence.

Finally, we stained the cells for phospho- $\mathrm{Rb}$ (Ser807/811). The retinoblastoma protein is a central regulator of the cell cycle, and becomes dephosphorylated in G0, but is progressively phosphorylated and inactivated as cells leave G0 and move through G1 into S phase (Figure 8D) (Spencer et al., 2013, Gookin et al., 2017). Rb phosphorylation was very low in NT control at high density but loss of TRAF3 induced a dramatic increase in phospho-Rb positive cells (Figure 8E, F). Together, these data strongly argue that the key effect of loss of TRAF3 is a failure to enter G0 under conditions that normally promote quiescence. 
A

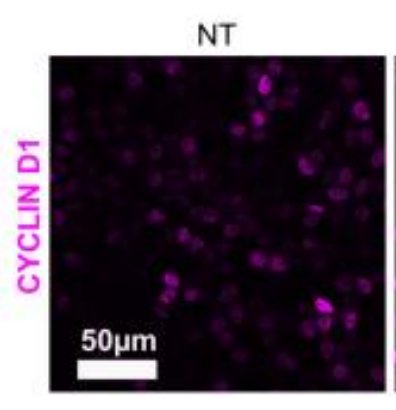

D
B

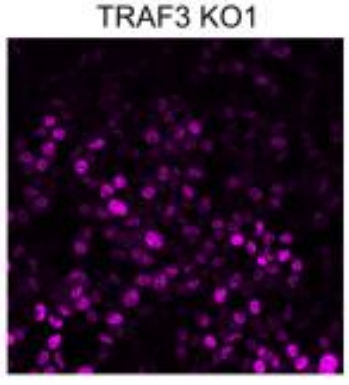

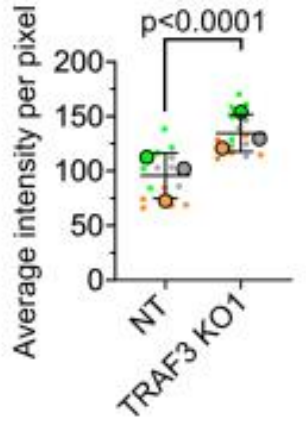

$\mathrm{E}$
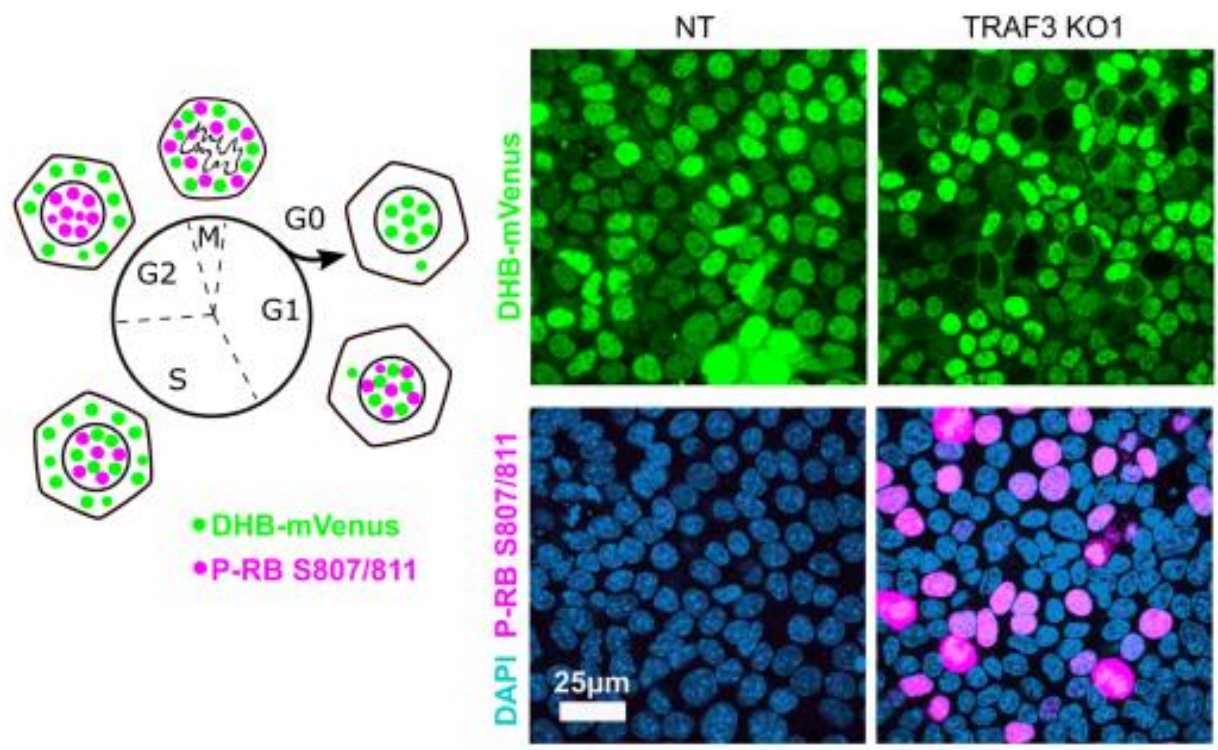

C
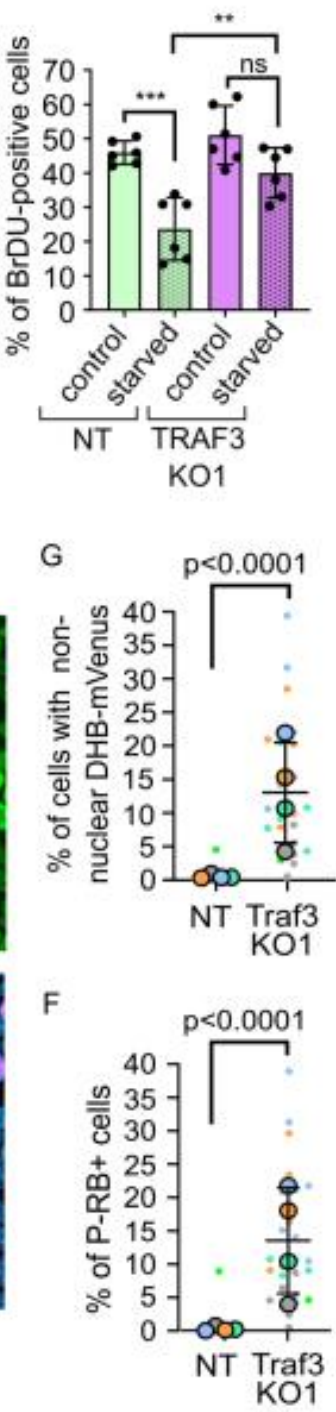

Figure 8. Loss of TRAF3 prevents cells from entering G0. A. NT and TRAF3 KO1 cells stained for CYCLIN D1. B. Quantifications of average CYCLIN D1 intensity in NT and TRAF3 KO cells. Data are presented as a SuperPlot $(n=3)$. P value was calculated by mixed model two-way ANOVA. C. NT and TRAF3 KO1 cells grown for $24 \mathrm{hrs}$ in regular media or media without FBS (starved) were treated with BrdU and analyzed by flow cytometry. D. A schematic of DHB-mVenus and phospho-RB S807/811 localization at different phases of cell cycle. E. NT and TRAF3 KO1 cells stably expressing DHB-mVenus were grown to 4 DPC and stained for phospho-RB S807/811 and DAPI. G. Quantifications of cells with non-nuclear DHB-mVenus localization. Data are presented as a SuperPlot $(n=4)$. $P$ value was calculated by mixed model two-way ANOVA. $F$. Quantification of phospho-RB positive cells. Data are presented as a SuperPlot $(n=4)$. $P$ value was calculated by mixed model two-way ANOVA. 


\section{DISCUSSION}

Epithelial cells possess intrinsic mechanisms to achieve and maintain an appropriate cell density, which is essential for normal tissue morphogenesis and maintenance (Fomicheva et al., 2019). Mechanisms of homeostatic cell density establishment are not fully understood. One of the most recognized pathways controlling cell density-dependent proliferation is the Hippo/YAP signaling pathway (Dupont et al., 2011). However, there are other mechanisms that control cell density independently from Hippo/YAP; for instance, LGL1/2 controls p27 levels in a densitydependent manner (Yamashita et al., 2015). With the goal of identifying novel components that control homeostatic cell density, we used an unbiased genome-wide CRISPR KO screen, in which we selected for cells that over-proliferate at high density. We uncovered a known (NF2) and two novel (TRAF3 and UBE2M) regulators of epithelial cell density. Loss of any of these genes results in increased cell proliferation at high density and multilayering of cells; however, proliferation at low cell density remains unaltered.

TRAF3 was of particular interest because this protein is essential for blood cell expansion and regulation of the immune response, but its functions in other tissues still remain unclear, although it is ubiquitously expressed (Yue et al., 2014). We discovered that loss of TRAF3 results in cell overgrowth in both mouse and human mammary gland cell lines, and mesenchymal cells (NIH 3T3 fibroblasts) as well as in primary mouse mammary gland organoids. We interrogated the mechanism of TRAF3-dependent proliferation control in mammary gland epithelial cells (Figure 8) and found that loss of TRAF3 specifically activates the non-canonical branch of NF-kB signaling, while having no effect on canonical NF-kB signaling. We further discovered that the non-canonical pathway is necessary for over-proliferation at high density in cells lacking TRAF3.

Our RNAseq data revealed that loss of TRAF3 does not induce the transcription of classical proliferation pathway components, including YAP/TAZ, PI3K/AKT, MAPK, TGF- $\beta$ and WNT signaling. We also demonstrated that over-proliferation caused by loss of TRAF3 is cell autonomous, as control cells did not over-proliferate when co-cultured with TRAF3 KO cells. Together, these data suggest that non-canonical NF-KB signaling does not positively drive proliferation but instead suppresses the ability of cells to exit the cell cycle. One key exit mechanism operates through induction of cyclin-dependent kinase inhibitors. For instance, in some epithelial cells p27 levels increase with density and high levels of p27 inhibit cell proliferation (Yamashita et al., 2015). However, we found no differences in levels of p27 or other CKIs (p21, p19 and p18) in cells lacking TRAF3 versus control EpH4 cells, although p21 levels do increase with increased cell density. Therefore, either EpH4 cells do not respond to CKIs or constitutive 
activation of the non-canonical NF-KB pathway overrides CKI-mediated cell cycle exit. Nonetheless, our data demonstrate that loss of TRAF3 prevents cells from entering quiescent state G0 as shown by increased CDK2 activity and RB phosphorylation.

RNAseq analysis revealed that loss of TRAF3 leads to the activation of immune response pathways, at least in part through non-canonical NF-kB signaling. Activated genes include antigen presentation, interferon response pathways, and genes responsible for foreign DNA and RNA recognition. Expression of these genes was reduced when p100 was deleted in theTRAF3 KO cells. However, certain genes induced in the TRAF3 KO cells, including adhesion molecules, superoxide-producing enzymes and chemokines, were not reduced by deletion of $\mathrm{p} 100$. These data reveal that a mechanism-independent of non-canonical NF-KB signaling can drive gene expression responses activated by loss of TRAF3.

The literature suggests that the loss or reduction of Traf3 expression or activation of noncanonical NF-kB signaling might be important for hyperplasia in response to infection or contribute to cancer development. It is known that epithelial cells can respond to infection by mounting an innate immune response. The non-canonical NF-KB pathway can be activated by contact with pathogens, and bronchial, intestinal, and mammary gland epithelia can each express a variety of innate immune factors that protect the organisms against infectious agents and attract immune cells (Strandberg et al., 2005, Philpott et al., 2001). H. pylori, a bacterium associated with the development of gastritis and gastric cancer, activates non-canonical NF-kB signaling in a stomach epithelial cell line, and in $H$. pylori-associated gastritis (Feige et al., 2018). Moreover, activation of the non-canonical NF-KB pathway in response to infection correlates with hyperplasia of the ear mucosa following otitis infection, although the mechanism was not investigated (Cho et al., 2016).

As discussed above, Traf3 is mutated, though at low frequency, in different cancers of epithelial origin (Zhu et al., 2018), and low expression is associated with worse outcomes. Noncanonical NF-kB signaling is also associated with different epithelial cancers, including breast cancer (Sovak et al., 1997, Rojo et al., 2016) and lung cancer (Dimitrakopoulos et al., 2019). Further work will be required to determine the impact of this pathway in cancer development. 


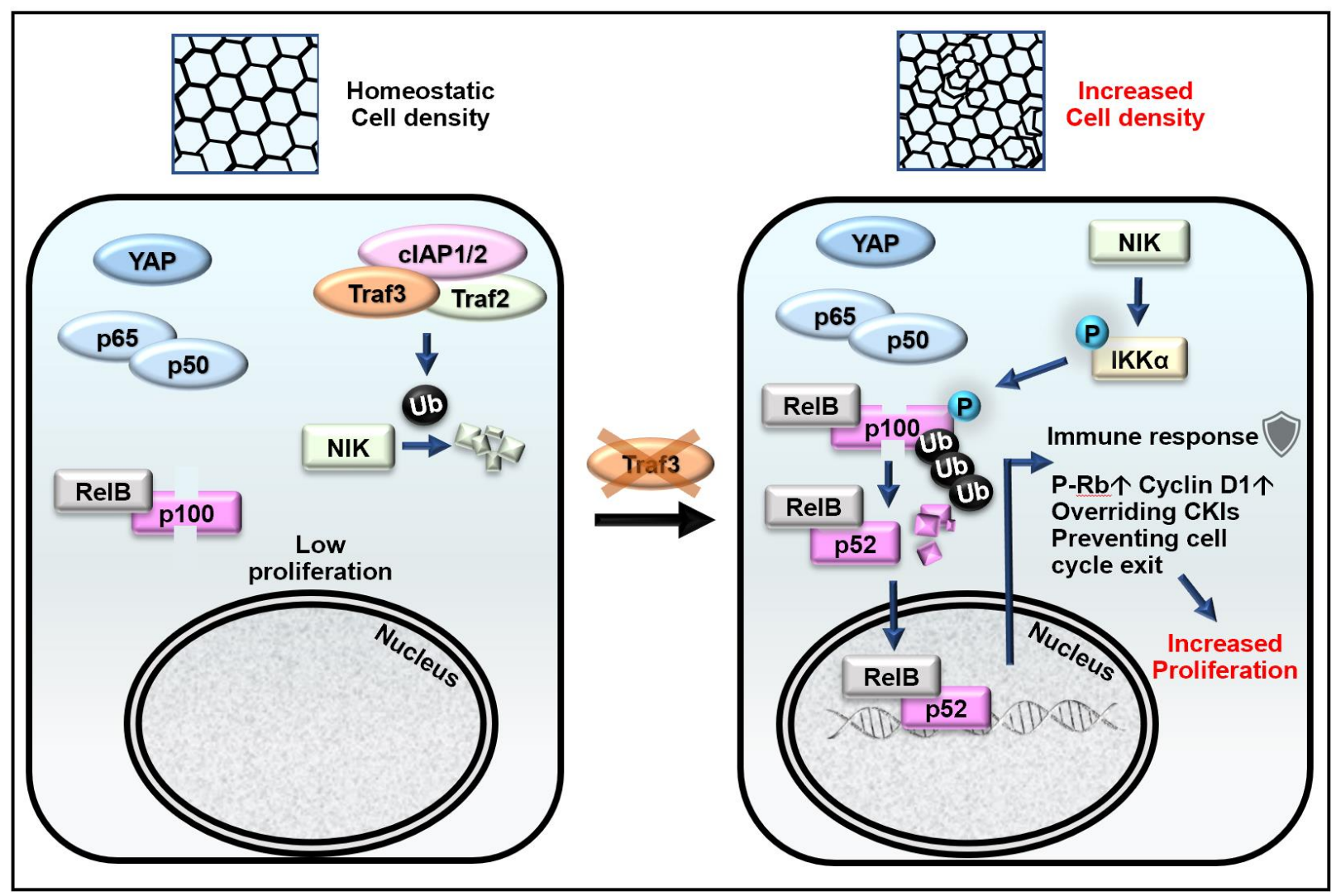

Figure 9. Model for the role of TRAF3 in density-dependent proliferation. Cells at high density rarely proliferate (on the left). They have active Hippo signaling (YAP is cytoplasmic), and inactive canonical NF-kB (p65/p50 is cytoplasmic) and non-canonical NF-kB signaling (NIK is low, p100 is not processed to p52, RELB is cytoplasmic). Upon loss of TRAF3, Hippo and canonical NF-kB signaling remain unaltered, but non-canonical NF-KB signaling is activated (on the right). NIK levels rise in the absence of TRAF3, activates the downstream cascade, resulting in increased p100 processing to p52. The RELB/p52 complex activates innate immune response genes, including antigen presentation and interferon pathway components. It also overrides CKIs, induces Cyclin D1 expression and prevents entering G0 as shown by increased number of cells with active CDK2 and phosphorylated Rb. Altogether it results in cell over-proliferation at high density. 


\section{MATERIALS AND METHODS}

Whole-genome CRISPR KO screen. Mouse CRISPR GeCKO v2 Knockout Pooled Library (Shalem et al., 2014, Sanjana et al., 2014) was purchased from Addgene. The library was amplified according to the developer's protocol (Shalem et al., 2014, Sanjana et al., 2014). Library lentiviruses were produced as described below. EpH4-FUCCI cells transduced with the library were grown for $10 \mathrm{~d}$ to allow time for gene-editing and depletion of the target proteins. The cells were then seeded at 100,000 cells $/ \mathrm{cm}^{2}$ and cultured for $4 \mathrm{~d}$, then trypsinized with $0.25 \%$ Trypsin (Gibco) and $4 \times 10^{7}$ cells (about 300 cells per sgRNA) were sorted on a FACSAria III for mCitrine+ (proliferating) cells. This population was replated, expanded, and resorted for mCitrine+ cells. This process was repeated for a total of three sorts. Genomic DNA from $4 \times 10^{7}$ cells before sorting, and after the $1^{\text {st }}, 2^{\text {nd }}$ and $3^{\text {rd }}$ rounds of sorting was purified using Blood \& Cell Culture DNA Midi

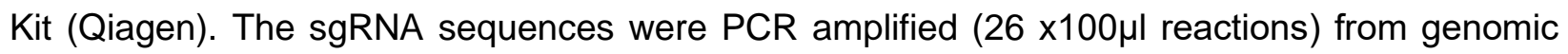
DNA $(\sim 260 \mu \mathrm{g})$ using adaptor primers developed by the Zhang laboratory. The products of the first PCR reactions were amplified again with Illumina index primers to add barcodes and Illumina adaptors. The products of this reaction were purified and sequenced on a Novaseq instrument. We utilized MAGeCK software (Li et al., 2014) to analyze the fastq files. A read count distribution graph was generated using RStudio.

Plasmid constructs and primers. ES-FUCCI (plasmid \# 62451 (Sladitschek and Neveu, 2015)) and DHB-mVenus (plasmid \#136461 (Spencer et al., 2013)) were purchased from Addgene. The p27 shRNA clone TRCN0000287390 in pLKO1 was obtained from the Sigma MISSION shRNA library. $p 27$ knockdown was tested by qPCR and compared to cells transduced with a scrambled non-targeting control shRNA (Figure 1 - figure supplement 3).

The sgRNAs used in this study are summarized in Figure 2 - figure supplement 2. sgRNAs were cloned into lentiCRISPR v2 vector at the $B s m B I$ restriction site using Zhang lab protocol (Shalem et al., 2014, Sanjana et al., 2014). p100 sgRNAs were cloned into a modified pLVTHM GFP vector between Clal and Mlul sites or into lentiCRISPR v2 vector.

Deletion of TRAF3 binding motif (amino acids 78-84) from wildtype NIK cDNA was performed by site-directed mutagenesis. NIK- $\triangle T 3$ cDNA was cloned into the pWPI mScarlet vector between BamHI and Ascl sites.

Cell culture, lentiviral transductions, transfections and chemicals. $\mathrm{EpH} 4$ cells were obtained from Dr. Jurgen Knoblich (Institute of Molecular Biotechnology, Vienna, Austria). 
HEK293T and MCF10a were obtained from the ATCC. EpH4 and HEK293T cells were cultured in DMEM (Gibco) supplemented with 10\% fetal bovine serum (Atlanta Biologicals), and 1x penicillin/streptomycin (Life Technologies). MCF10a cells were cultured in DMEM/F12 media (Gibco) supplemented with 5\% Horse Serum (Gibco), EGF 20 ng/ml (Sigma), hydrocortisone 0.5 $\mathrm{mg} / \mathrm{ml}$ (Sigma), cholera toxin $100 \mathrm{ng} / \mathrm{ml}$ (MP Biomedicals), insulin $10 \mu \mathrm{g} / \mathrm{ml}$ (Sigma), and 1x penicillin/streptomycin (Life Technologies). EpH4 cells were seeded at 100,000 cells/cm ${ }^{2}$ and cultured for 1 or $4 \mathrm{~d}$. MCF10a cells were seeded at 100,000 cells/cm ${ }^{2}$ and cultured for $5 \mathrm{~d}$. Lentiviruses were produced by calcium phosphate transfection of HEK293T cells with lentivectors and lentiviral packaging vectors psPAX2 and pMD2.G. Lentiviruses were collected and concentrated $48 \mathrm{hrs}$ after transduction, utilizing Amicon centrifugal filter units. EpH4 and MCF10a cells were transduced by lentiviruses by shaking cells and viruses in suspension at $400 \mathrm{rpm}, 37^{\circ} \mathrm{C}$ for $1 \mathrm{hr}$. Transduced cells were selected by puromycin (CRISPR v2 vectors) or FACS (pWPI mScarlet, pLVTHM GFP and DHB-mVenus vectors). EpH4 cells used for mixing experiments were NT pWPI mScarlet, NT pLVTHM GFP, and Traf3 KO1 pWPI mScarlet. SMAC mimetic BV6 was purchased from ApexBio (B4653).

To develop the EpH4 ES-FUCCI stable cell line we linearized the ES-FUCCI vector with Asel and transduced cells using Xfect (Clontech) according to the manufacturer's protocol. Cells were selected with $300 \mu \mathrm{g} / \mathrm{mL}$ Hygromycin followed by FAC sorting of mCitrine+ and/or mCherry+ cells.

Flow cytometry analysis. Cells were treated with $3 \mu \mathrm{g} / \mathrm{ml}$ BrdU (Sigma-Aldrich) for $1 \mathrm{hr}$, then washed in sterile PBS and trypsinized. Trypsin was blocked with complete medium plus $50 \mu \mathrm{g} / \mathrm{mL}$ DNase to reduce clumping of cells. Cells were pelleted, incubated in $5 \mathrm{mM}$ EDTA in PBS on ice for $10 \mathrm{~min}$ and fixed in $4 \%$ paraformaldehyde for $15 \mathrm{~min}$ at room temperature. BrdU incorporation was detected after treatment with $2 \mathrm{~N} \mathrm{HCl}$ for 20 min at $37^{\circ} \mathrm{C}$, washing with $1.5 \mathrm{M} \mathrm{Na2B} 4 \mathrm{O} 7$, blocking in Western Blocking reagent (Roche) and staining with anti-BrdU antibodies (1:800, Abcam, ab6326). Cells were analyzed using a Fortessa flow cytometer and analyzed using FlowJo.

Immunoblotting. Cells were lysed in buffer containing $0.1 \%$ Triton-X100, 20mM HEPES (pH 7.4), $50 \mathrm{mM} \mathrm{NaCl}$, and 2mM EDTA supplemented with a protease inhibitor cocktail (Roche), Calyculin A, and PhosStop phosphatase inhibitors (Roche). Cell lysates were briefly sonicated and centrifuged at $16,100 \mathrm{~g}$ for $10 \mathrm{~min}$. After centrifugation, the soluble fraction was boiled with SDS sample buffer for $5 \mathrm{~min}$. Antibodies used for Western blotting were as follows: rabbit anti-MERLIN 
(1:750, CST, 6995S), mouse anti-TRAF3 (1:200, Santa Cruz, sc-6933), rabbit anti-UBE2M (1:500, Proteintech,14520-1-AP), rabbit anti-NF-kB2 p100/p52 (1:750, CST, 4882), rabbit antiNIK (1:500, CST, 4994S), rabbit anti-RELB (1:1000, Abcam, ab180127), NF-kB Pathway Sampler (1:1000, CST, 9936), mouse p27 (1:1000, BD Transduction Laboratories, 610241), mouse p21 (1:1000, Invitrogen, ma5-14353), rabbit p19 (1:200, Santa Cruz, sc-1063), rabbit p18 (1:200, Santa Cruz, sc-1064), rabbit anti-GAPDH (1:2000, CST, 2118S), mouse anti- $\alpha$-tubulin (1:4000, Sigma-Aldrich, T-9026), mouse anti-actin (1:4000, Sigma-Aldrich, A4700).

Immunofluorescence staining, image acquisition and analysis. Cells were grown on LabTek II chamber slides (Thermo Scientific) for the indicated times and fixed with $4 \%$ paraformaldehyde at room temperature for $15 \mathrm{~min}$. Cells were permeabilized with $0.2 \%$ Triton $\mathrm{X}-100$, blocked in 1xWestern Blocking Reagent (Roche) and labeled for IF imaging. We utilized the following primary antibodies and dyes: rat anti-BrdU antibodies (1:800, Abcam, ab6326), rabbit anti-RELB (1:300, Abcam, ab180127), rabbit anti-YAP (1:200, Novus Biologicals, NB110-58358), rabbit phospho-RB Ser807/811 (1:1000, CST, 8516S), rabbit anti-CYCLIN D1 (1:50, Invitrogen, MA511387), Hoechst 33342 (Life Technologies), DAPI (1:500, Sigma-Aldrich, 422801), DRAQ5 (1:1000, CST) to label nuclei. Secondary labelling was performed using Alexa Fluor secondary antibodies (1:500-1:1000, Life Technologies). Samples were mounted using Fluoromount $G$ (Electron Microscopy Sciences). Laser scanning confocal images were acquired using 20x/0.75 Plan Apo or 100x/1.40 Plan Apo oil immersion objectives on a Nikon A1R inverted confocal microscope (Nikon Instruments Inc). Epifluorescence images were acquired using an EVOS FL inverted microscope (Life Technologies). Fiji software was used for post-acquisition processing.

Fiji Temporal Color Code function (fire color scale) was used for depth color coding of cells for visualization of multilayering. To measure the percent of multilayering in $\mathrm{KO}$ cells, we used Fiji software to process confocal image stacks of cells that had been grown to high density and stained for a nuclear marker. A single slice above the monolayer (about $8 \mu \mathrm{m}$ above the center of the nuclei in the first layer of cells) was processed using Gaussian blur and Threshold to create a binary mask. It was analyzed using Measure particles function to determine the percent of total area that is above the monolayer. Data were collected for 5 fields of view in 3 biological repeats.

Nuclear/cytoplasmic ratio of YAP was measured using the ImageJ Intensity Ratio Nuclei CytoplasmTool:(https://github.com/MontpellierRessourcesImagerie/imagej_macros_and_scripts/ wiki/Intensity-Ratio-Nuclei-Cytoplasm-Tool) 
Real-time qPCR. Total RNA was extracted with TRIzol (Life Technologies). cDNA was reverse transcribed using the SuperScript III First-Strand Synthesis System (Invitrogen). qPCR was performed with triplicate replicates on a BioRad CFX96 Thermocycler and analyzed using the $\Delta \Delta \mathrm{Ct}$ method. Expression levels were calculated relative to Gapdh. $p 27$ levels were assessed using p27 primers. The enrichment of cells containing sh-p27 after FACS was assessed using puromycin resistance gene primers, because the Puro cassette was integrated into the cell genome together with the $p 27$ shRNA. Sequences of primers are summarized in Figure 1 - figure supplement 3.

RNA sequencing. NT, TRAF3 KO1 and TRAF3/p100 double KO EpH4-FUCCI cells were sorted for non-proliferating cells (mCherry+) by FACS. RNA from NT, TRAF3 KO1 and TRAF3/p100 double KO cells from 2 experimental repeats was isolated using the RNeasy Mini Kit (Qiagen). RNA quality control was performed using a 2100 Bioanalyzer (Agilent Technologies). Samples had RNA integrity numbers in the range 8.1-9.3. Sequencing was performed using the NovaSeq 6000 Sequencing System (Illumina, San Diego, CA). Data were processed and analyzed with CLC Genomics Workbench and Ingenuity Pathway Analysis (Qiagen).

Mouse mammary gland organoids. Mammary glands were isolated from 8-week-old $\mathrm{C} 3 \mathrm{H}$ as described previously (Pasic et al., 2011). Cells were then briefly treated with $0.25 \%$ Trypsin and filtered through a $40 \mu \mathrm{m}$ strainer. Primary mammary cells were transduced with lentiCRISPR v2 NT control and Traf3 KO1 and grown for $8 \mathrm{~d}$ in 50\% Matrigel (Corning) supplemented with Organoid Growth Medium (DMEM/F12 (Gibco), 5 ng/mL EGF (Sigma), 3 ng/mL mFGF2 (R\&D Systems), 1xITS (Millipore Sigma)). Then organoids were then fixed with PFA and immunostained.

Statistical analysis. Data were tested for normality by Shapiro-Wilk test and then analyzed by Student's t-test, one-way ANOVA, or mixed model two-way ANOVA statistical test using GraphPad Prism software. When using ANOVA, post hoc analysis was done using Tukey or Dunnett multiple comparison tests. All statistical analysis was considered significant at $p<0.05$. Data presented as SuperPlots (Lord et al., 2020) combine individual measurements (small dots color-coded for each replicate), mean values for each replicate (large dots color-coded for each replicate), and mean \pm std. 
Data availability. All data that support the findings of this study are available within the article and its Supplementary Information, or from the authors upon reasonable request. RNAseq data have been submitted to the GEO repository.

\section{Acknowledgements}

This work was supported by NCI grant R35CA132898 to I.G.M. We would like to thank members of the Macara lab for their valuable feedback, as well as Christian de Caestecker, Christian Meyer and Daria Episheva for the help with processing Illumina data for the CRISPR screen. We also thank Vivian Gama and Edward Levine lab for sharing antibodies. Flow Cytometry experiments were performed in the VMC Flow Cytometry Shared Resource; Illumina sequencing and RNA-seq were performed by Vanderbilt Technologies for Advanced Genomics. These resources are supported by the Vanderbilt Ingram Cancer Center (P30 CA68485) and the Vanderbilt Digestive Disease Research Center (DK058404).

\section{REFERENCES}

ARAGONA, M., PANCIERA, T., MANFRIN, A., GIULITTI, S., MICHIELIN, F., ELVASSORE, N., DUPONT, S. \& PICCOLO, S. 2013. A mechanical checkpoint controls multicellular growth through YAP/TAZ regulation by actin-processing factors. Cell, 154, 1047-1059.

CAO, Y., BONIZZI, G., SEAGROVES, T. N., GRETEN, F. R., JOHNSON, R., SCHMIDT, E. V. \& KARIN, M. 2001. IKKalpha provides an essential link between RANK signaling and cyclin D1 expression during mammary gland development. Cell, 107, 763-75.

CHO, C. G., PAK, K., WEBSTER, N., KURABI, A. \& RYAN, A. F. 2016. Both canonical and non-canonical NFkappaB activation contribute to the proliferative response of the middle ear mucosa during bacterial infection. Innate Immun, 22, 626-634.

CLAUDIO, E., BROWN, K., PARK, S., WANG, H. \& SIEBENLIST, U. 2002. BAFF-induced NEMO-independent processing of NF-kappa B2 in maturing B cells. Nat Immunol, 3, 958-65.

COOPE, H. J., ATKINSON, P. G., HUHSE, B., BELICH, M., JANZEN, J., HOLMAN, M. J., KLAUS, G. G., JOHNSTON, L. H. \& LEY, S. C. 2002. CD40 regulates the processing of NF-kappaB2 p100 to p52. EMBO J, 21, 5375-85.

CORDENONSI, M., ZANCONATO, F., AZZOLIN, L., FORCATO, M., ROSATO, A., FRASSON, C., INUI, M., MONTAGNER, M., PARENTI, A. R., POLETTI, A., DAIDONE, M. G., DUPONT, S., BASSO, G., BICCIATO, S. \& PICCOLO, S. 2011. The Hippo Transducer TAZ Confers Cancer Stem Cell-Related Traits on Breast Cancer Cells. Cell, 147, 759-772.

DEJARDIN, E., DROIN, N. M., DELHASE, M., HAAS, E., CAO, Y., MAKRIS, C., LI, Z. W., KARIN, M., WARE, C. F. \& GREEN, D. R. 2002. The lymphotoxin-beta receptor induces different patterns of gene expression via two NF-kappaB pathways. Immunity, 17, 525-35.

DEMICCO, E. G., KAVANAGH, K. T., ROMIEU-MOUREZ, R., WANG, X., SHIN, S. R., LANDESMAN-BOLLAG, E., SELDIN, D. C. \& SONENSHEIN, G. E. 2005. RelB/p52 NF-kappaB complexes rescue an early delay in mammary gland development in transgenic mice with targeted superrepressor lkappaB- 
alpha expression and promote carcinogenesis of the mammary gland. Mol Cell Biol, 25, 10136-

47.

DIMITRAKOPOULOS, F. D., ANTONACOPOULOU, A. G., KOTTOROU, A. E., PANAGOPOULOS, N., KALOFONOU, F., SAMPSONAS, F., SCOPA, C., KALOFONOU, M., KOUTRAS, A., MAKATSORIS, T., DOUGENIS, D., PAPADAKI, H., BROCK, M. \& KALOFONOS, H. P. 2019. Expression Of Intracellular Components of the NF-kappaB Alternative Pathway (NF-kappaB2, RelB, NIK and Bcl3) is Associated With Clinical Outcome of NSCLC Patients. Sci Rep, 9, 14299.

DUPONT, S., MORSUT, L., ARAGONA, M., ENZO, E., GIULITTI, S., CORDENONSI, M., ZANCONATO, F., LE DIGABEL, J., FORCATO, M., BICCIATO, S., ELVASSORE, N. \& PICCOLO, S. 2011. Role of YAP/TAZ in mechanotransduction. Nature, 474, 179-83.

EISENHOFFER, G. T., LOFTUS, P. D., YOSHIGI, M., OTSUNA, H., CHIEN, C. B., MORCOS, P. A. \& ROSENBLATT, J. 2012. Crowding induces live cell extrusion to maintain homeostatic cell numbers in epithelia. Nature, 484, 546-9.

EWALD, A. J., BRENOT, A., DUONG, M., CHAN, B. S. \& WERB, Z. 2008. Collective epithelial migration and cell rearrangements drive mammary branching morphogenesis. Dev Cell, 14, 570-81.

FEIGE, M. H., VIETH, M., SOKOLOVA, O., TAGER, C. \& NAUMANN, M. 2018. Helicobacter pylori induces direct activation of the lymphotoxin beta receptor and non-canonical nuclear factor-kappa $B$ signaling. Biochim Biophys Acta Mol Cell Res, 1865, 545-550.

FOMICHEVA, M., TROSS, E. M. \& MACARA, I. G. 2019. Polarity proteins in oncogenesis. Curr Opin Cell Biol, 62, 26-30.

GOOKIN, S., MIN, M., PHADKE, H., CHUNG, M., MOSER, J., MILLER, I., CARTER, D. \& SPENCER, S. L. 2017. A map of protein dynamics during cell-cycle progression and cell-cycle exit. PLoS Biol, 15, e2003268.

GUAN, K., WEI, C., ZHENG, Z., SONG, T., WU, F., ZHANG, Y., CAO, Y., MA, S., CHEN, W., XU, Q., XIA, W., GU, J., HE, X. \& ZHONG, H. 2015. MAVS Promotes Inflammasome Activation by Targeting ASC for K63-Linked Ubiquitination via the E3 Ligase TRAF3. J Immunol, 194, 4880-90.

HACKER, H., REDECKE, V., BLAGOEV, B., KRATCHMAROVA, I., HSU, L. C., WANG, G. G., KAMPS, M. P., RAZ, E., WAGNER, H., HACKER, G., MANN, M. \& KARIN, M. 2006. Specificity in Toll-like receptor signalling through distinct effector functions of TRAF3 and TRAF6. Nature, 439, 204-7.

HAUER, J., PUSCHNER, S., RAMAKRISHNAN, P., SIMON, U., BONGERS, M., FEDERLE, C. \& ENGELMANN, H. 2005. TNF receptor (TNFR)-associated factor (TRAF) 3 serves as an inhibitor of TRAF2/5mediated activation of the noncanonical NF-kappaB pathway by TRAF-binding TNFRs. Proc NatI Acad Sci U S A, 102, 2874-9.

HE, J. Q., ZARNEGAR, B., OGANESYAN, G., SAHA, S. K., YAMAZAKI, S., DOYLE, S. E., DEMPSEY, P. W. \& CHENG, G. 2006. Rescue of TRAF3-null mice by p100 NF-kappa B deficiency. J Exp Med, 203, 2413-8.

HOEBE, K. \& BEUTLER, B. 2006. TRAF3: a new component of the TLR-signaling apparatus. Trends Mol Med, 12, 187-9.

LALANI, A. I., MOORE, C. R., LUO, C., KREIDER, B. Z., LIU, Y., MORSE, H. C., 3RD \& XIE, P. 2015. Myeloid cell TRAF3 regulates immune responses and inhibits inflammation and tumor development in mice. J Immunol, 194, 334-48.

LI, W., XU, H., XIAO, T., CONG, L., LOVE, M. I., ZHANG, F., IRIZARRY, R. A., LIU, J. S., BROWN, M. \& LIU, X. S. 2014. MAGeCK enables robust identification of essential genes from genome-scale CRISPR/Cas9 knockout screens. Genome Biol, 15, 554.

LIAO, G., ZHANG, M., HARHAJ, E. W. \& SUN, S. C. 2004. Regulation of the NF-kappaB-inducing kinase by tumor necrosis factor receptor-associated factor 3-induced degradation. J Biol Chem, 279, 26243-50. 
LIN, W. W., YI, Z., STUNZ, L. L., MAINE, C. J., SHERMAN, L. A. \& BISHOP, G. A. 2015. The adaptor protein TRAF3 inhibits interleukin- 6 receptor signaling in B cells to limit plasma cell development. Sci Signal, 8, ra88.

LORD, S. J., VELLE, K. B., MULLINS, R. D. \& FRITZ-LAYLIN, L. K. 2020. SuperPlots: Communicating reproducibility and variability in cell biology. J Cell Biol, 219.

LYDEARD, J. R., SCHULMAN, B. A. \& HARPER, J. W. 2013. Building and remodelling Cullin-RING E3 ubiquitin ligases. EMBO Rep, 14, 1050-61.

MA, S., MENG, Z., CHEN, R. \& GUAN, K. L. 2019. The Hippo Pathway: Biology and Pathophysiology. Annu Rev Biochem, 88, 577-604.

MICHALLET, M. C., MEYLAN, E., ERMOLAEVA, M. A., VAZQUEZ, J., REBSAMEN, M., CURRAN, J., POECK, H., BSCHEIDER, M., HARTMANN, G., KONIG, M., KALINKE, U., PASPARAKIS, M. \& TSCHOPP, J. 2008. TRADD protein is an essential component of the RIG-like helicase antiviral pathway. Immunity, 28, 651-61.

MOORE, C. R., LIU, Y., SHAO, C., COVEY, L. R., MORSE, H. C., 3RD \& XIE, P. 2012. Specific deletion of TRAF3 in B lymphocytes leads to B-lymphoma development in mice. Leukemia, 26, 1122-7.

NAGY, A., LANCZKY, A., MENYHART, O. \& GYORFFY, B. 2018. Validation of miRNA prognostic power in hepatocellular carcinoma using expression data of independent datasets. Sci Rep, 8, 9227.

OGANESYAN, G., SAHA, S. K., GUO, B., HE, J. Q., SHAHANGIAN, A., ZARNEGAR, B., PERRY, A. \& CHENG, G. 2006. Critical role of TRAF3 in the Toll-like receptor-dependent and-independent antiviral response. Nature, 439, 208-11.

PARK, S. G., CHUNG, C., KANG, H., KIM, J. Y. \& JUNG, G. 2006. Up-regulation of cyclin D1 by HBx is mediated by NF-kappaB2/BCL3 complex through kappaB site of cyclin D1 promoter. J Biol Chem, 281, 31770-7.

PASIC, L., EISINGER-MATHASON, T. S., VELAYUDHAN, B. T., MOSKALUK, C. A., BRENIN, D. R., MACARA, I. G. \& LANNIGAN, D. A. 2011. Sustained activation of the HER1-ERK1/2-RSK signaling pathway controls myoepithelial cell fate in human mammary tissue. Genes Dev, 25, 1641-53.

PETRILLI, A. M. \& FERNANDEZ-VALLE, C. 2016. Role of Merlin/NF2 inactivation in tumor biology. Oncogene, 35, 537-48.

PHILPOTT, D. J., GIRARDIN, S. E. \& SANSONETTI, P. J. 2001. Innate immune responses of epithelial cells following infection with bacterial pathogens. Curr Opin Immunol, 13, 410-6.

RAMAKRISHNAN, P., WANG, W. \& WALLACH, D. 2004. Receptor-specific signaling for both the alternative and the canonical NF-kappaB activation pathways by NF-kappaB-inducing kinase. Immunity, 21, 477-89.

ROCHA, S., MARTIN, A. M., MEEK, D. W. \& PERKINS, N. D. 2003. p53 represses cyclin D1 transcription through down regulation of $\mathrm{Bcl}-3$ and inducing increased association of the p52 NF-kappaB subunit with histone deacetylase 1. Mol Cell Biol, 23, 4713-27.

ROJO, F., GONZALEZ-PEREZ, A., FURRIOL, J., NICOLAU, M. J., FERRER, J., BURGUES, O., SABBAGHI, M., GONZALEZ-NAVARRETE, I., CRISTOBAL, I., SERRANO, L., ZAZO, S., MADOZ, J., SERVITJA, S., TUSQUETS, I., ALBANELL, J., LLUCH, A., ROVIRA, A. \& EROLES, P. 2016. Non-canonical NF-kappaB pathway activation predicts outcome in borderline oestrogen receptor positive breast carcinoma. Br J Cancer, 115, 322-31.

SANJANA, N. E., SHALEM, O. \& ZHANG, F. 2014. Improved vectors and genome-wide libraries for CRISPR screening. Nat Methods, 11, 783-784.

SHALEM, O., SANJANA, N. E., HARTENIAN, E., SHI, X., SCOTT, D. A., MIKKELSON, T., HECKL, D., EBERT, B. L., ROOT, D. E., DOENCH, J. G. \& ZHANG, F. 2014. Genome-scale CRISPR-Cas9 knockout screening in human cells. Science, 343, 84-87.

SLADITSCHEK, H. L. \& NEVEU, P. A. 2015. MXS-Chaining: A Highly Efficient Cloning Platform for Imaging and Flow Cytometry Approaches in Mammalian Systems. PLoS One, 10, e0124958. 
SOVAK, M. A., BELLAS, R. E., KIM, D. W., ZANIESKI, G. J., ROGERS, A. E., TRAISH, A. M. \& SONENSHEIN, G. E. 1997. Aberrant nuclear factor-kappaB/Rel expression and the pathogenesis of breast cancer. $J$ Clin Invest, 100, 2952-60.

SPENCER, S. L., CAPPELL, S. D., TSAI, F. C., OVERTON, K. W., WANG, C. L. \& MEYER, T. 2013. The proliferation-quiescence decision is controlled by a bifurcation in CDK2 activity at mitotic exit. Cell, 155, 369-83.

STRANDBERG, Y., GRAY, C., VUOCOLO, T., DONALDSON, L., BROADWAY, M. \& TELLAM, R. 2005. Lipopolysaccharide and lipoteichoic acid induce different innate immune responses in bovine mammary epithelial cells. Cytokine, 31, 72-86.

SUN, S. C. 2017. The non-canonical NF-kappaB pathway in immunity and inflammation. Nat Rev Immunol, 17, 545-558.

XIE, P., POOVASSERY, J., STUNZ, L. L., SMITH, S. M., SCHULTZ, M. L., CARLIN, L. E. \& BISHOP, G. A. 2011. Enhanced Toll-like receptor (TLR) responses of TNFR-associated factor 3 (TRAF3)-deficient B lymphocytes. J Leukoc Biol, 90, 1149-57.

YAMASHITA, K., IDE, M., FURUKAWA, K. T., SUZUKI, A., HIRANO, H. \& OHNO, S. 2015. Tumor suppressor protein Lgl mediates $\mathrm{G} 1$ cell cycle arrest at high cell density by forming an LgI-VprBP-DDB1 complex. Mol Biol Cell, 26, 2426-38.

YI, Z., LIN, W. W., STUNZ, L. L. \& BISHOP, G. A. 2014. The adaptor TRAF3 restrains the lineage determination of thymic regulatory $T$ cells by modulating signaling via the receptor for IL-2. Nat Immunol, 15, 866-74.

YUE, F., CHENG, Y., BRESCHI, A., VIERSTRA, J., WU, W., RYBA, T., SANDSTROM, R., MA, Z., DAVIS, C., POPE, B. D., SHEN, Y., PERVOUCHINE, D. D., DJEBALI, S., THURMAN, R. E., KAUL, R., RYNES, E., KIRILUSHA, A., MARINOV, G. K., WILLIAMS, B. A., TROUT, D., AMRHEIN, H., FISHER-AYLOR, K., ANTOSHECHKIN, I., DESALVO, G., SEE, L. H., FASTUCA, M., DRENKOW, J., ZALESKI, C., DOBIN, A., PRIETO, P., LAGARDE, J., BUSSOTTI, G., TANZER, A., DENAS, O., LI, K., BENDER, M. A., ZHANG, M., BYRON, R., GROUDINE, M. T., MCCLEARY, D., PHAM, L., YE, Z., KUAN, S., EDSALL, L., WU, Y. C., RASMUSSEN, M. D., BANSAL, M. S., KELLIS, M., KELLER, C. A., MORRISSEY, C. S., MISHRA, T., JAIN, D., DOGAN, N., HARRIS, R. S., CAYTING, P., KAWLI, T., BOYLE, A. P., EUSKIRCHEN, G., KUNDAJE, A., LIN, S., LIN, Y., JANSEN, C., MALLADI, V. S., CLINE, M. S., ERICKSON, D. T., KIRKUP, V. M., LEARNED, K., SLOAN, C. A., ROSENBLOOM, K. R., LACERDA DE SOUSA, B., BEAL, K., PIGNATELLI, M., FLICEK, P., LIAN, J., KAHVECI, T., LEE, D., KENT, W. J., RAMALHO SANTOS, M., HERRERO, J., NOTREDAME, C., JOHNSON, A., VONG, S., LEE, K., BATES, D., NERI, F., DIEGEL, M., CANFIELD, T., SABO, P. J., WILKEN, M. S., REH, T. A., GISTE, E., SHAFER, A., KUTYAVIN, T., HAUGEN, E., DUNN, D., REYNOLDS, A. P., NEPH, S., HUMBERT, R., HANSEN, R. S., DE BRUIJN, M., et al. 2014. A comparative encyclopedia of DNA elements in the mouse genome. Nature, 515, 355-64.

ZAPATA, J. M., LLOBET, D., KRAJEWSKA, M., LEFEBVRE, S., KRESS, C. L. \& REED, J. C. 2009. Lymphocytespecific TRAF3 transgenic mice have enhanced humoral responses and develop plasmacytosis, autoimmunity, inflammation, and cancer. Blood, 113, 4595-603.

ZARNEGAR, B., YAMAZAKI, S., HE, J. Q. \& CHENG, G. 2008. Control of canonical NF-kappaB activation through the NIK-IKK complex pathway. Proc Natl Acad Sci U S A, 105, 3503-8.

ZHANG, J., WARREN, M. A., SHOEMAKER, S. F. \& IP, M. M. 2007. NFkappaB1/p50 is not required for tumor necrosis factor-stimulated growth of primary mammary epithelial cells: implications for NFkappaB2/p52 and RelB. Endocrinology, 148, 268-78.

ZHOU, W., XU, J., TAN, M., LI, H., LI, H., WEI, W. \& SUN, Y. 2018. UBE2M Is a Stress-Inducible Dual E2 for Neddylation and Ubiquitylation that Promotes Targeted Degradation of UBE2F. Mol Cell, 70, 1008-1024 e6.

ZHU, S., JIN, J., GOKHALE, S., LU, A. M., SHAN, H., FENG, J. \& XIE, P. 2018. Genetic Alterations of TRAF Proteins in Human Cancers. Front Immunol, 9, 2111. 
bioRxiv preprint doi: https://doi.org/10.1101/2020.10.02.324301; this version posted October 2, 2020. The copyright holder for this preprint (which was not certified by peer review) is the author/funder, who has granted bioRxiv a license to display the preprint in perpetuity. It is made available under aCC-BY-NC-ND 4.0 International license. 